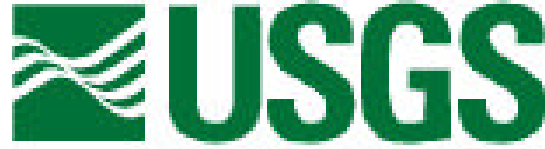

science for a changing world'
Texas A\& M University-Corpus Christi

The Island University

\title{
A Preliminary Survey of Marine Contamination from Mining-related Activities on Marinduque Island, Philippines: Porewater Toxicity and Chemistry Results from a Field Trip - October 14-19, 2000
}

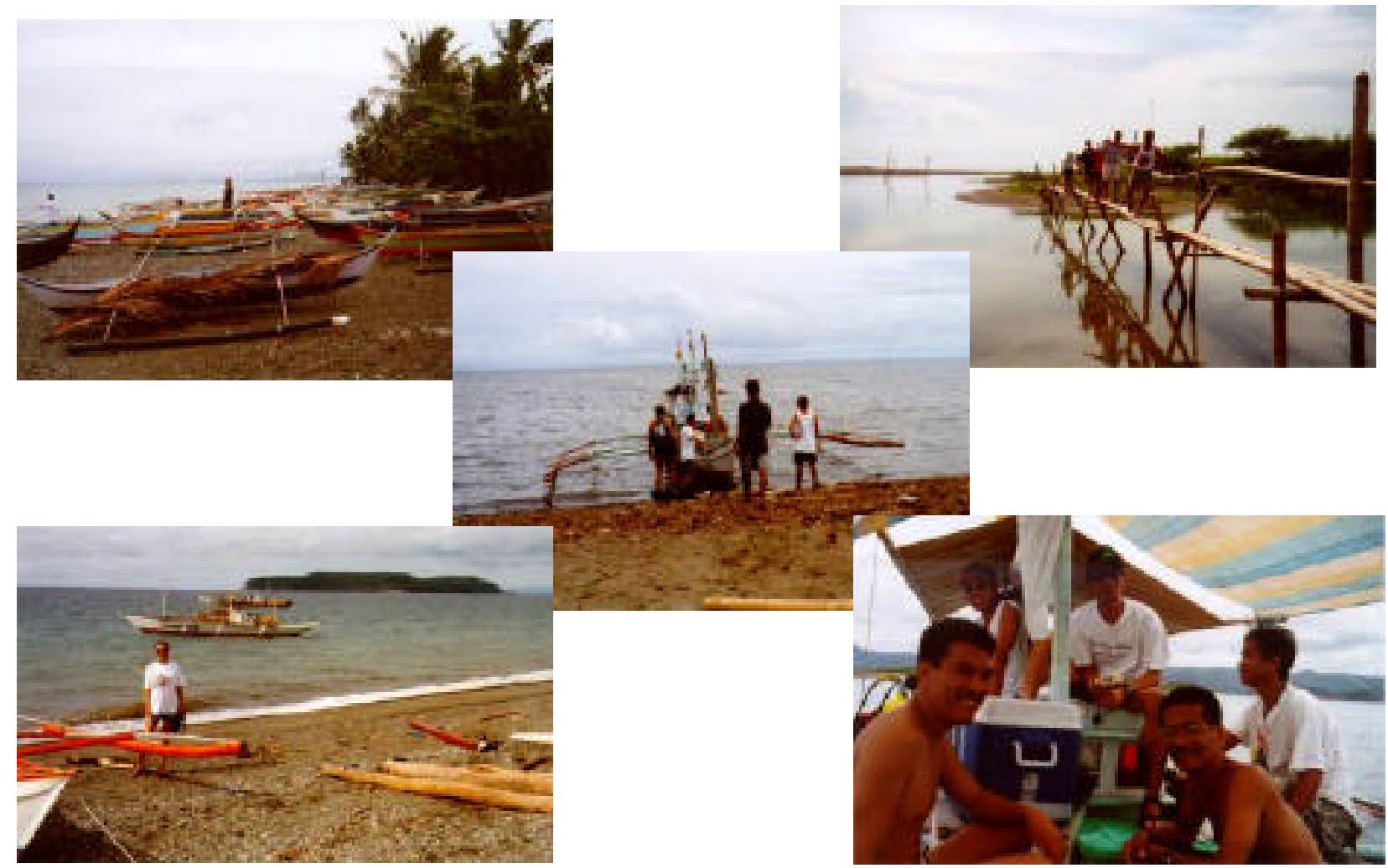

By R. Scott Carr ${ }^{1}$, Marion Nipper ${ }^{2}$, and Geoffrey S. Plumlee ${ }^{3}$

'U.S. Geological Survey, Marine Ecotoxicology Research Station, TAMU-CC, NRC Suite 3200, 6300 Ocean Drive, Corpus Christi, TX 78412

${ }^{2}$ Texas A \& M University - Corpus Christi, Center for Coastal Studies, NRC Suite 3200, 6300 Ocean Drive, Corpus Christi, TX 78412

${ }^{3}$ U.S. Geological Survey, MS964 Federal Center, Denver, CO 80225

\section{Open File Report 01-441}

\section{TAMU-CC-0105-CCS}

The content of this document has not been reviewed for conformity with U.S.Geological Survey editorial standards. The use of firm, trade, and brand names is for identification purposes only and does not constitute endorsement by the U.S. Government.

This report is available online at: http://geology.cr.usgs.gov/pub/open-file-reports/ofr-01-0441

\section{U.S.DEPARTMENT OF THE INTERIOR U.S.GEOLOGICAL SURVEY}




\title{
A Preliminary Survey of Marine Contamination from Mining-related Activities on Marinduque Island, Philippines: Porewater Toxicity and Chemistry Results from a Field Trip - October 14-19, 2000
}

\author{
By R. Scott Carr, Marion Nipper, and Geoffrey S. Plumlee
}

\section{Executive Summary}

As a follow-up of an initial overview of environmental problems caused by mining activities on Marinduque Island, Philippines, USGS and TAMU-CC scientists went to Marinduque in October 2000 to do a preliminary assessment of potential impacts of mining-related activities on the marine environment. Like the previous visit in May 2000, the marine assessment was conducted at the invitation of Philippine Congressman Edmund O. Reyes.

In this report we present the results of sediment porewater toxicity tests and chemical analyses. Toxicity tests consist of laboratory analyses for the assessment of adverse effects caused by environmental contaminants to animals or plants. Sediments (sand or mud) are known to accumulate contaminants (e.g., copper and other heavy metals). Therefore, it is common to perform toxicity tests using different phases of the sedimentary environment in order to analyze adverse effects of contaminants accumulated in the sediment. Sediment pore water (or interstitial water, i.e., the water distributed among the sediment grains) is a sedimentary phase which controls the bioavailability of contaminants to bottom dwelling aquatic organisms (both plants and animals).

There are several different kinds of organisms with which toxicity tests can be performed. Among those, tests with sea urchin early life stages (gametes and embryos) are very common due to their high sensitivity to contaminants, ease of maintenance under laboratory conditions, and ecological importance, particularly in coral reefs. The basis of these tests is the exposure of gametes or embryos to the pore water to be analyzed for toxicity. If the pore water contains contaminants in levels that can adversely affect a number of marine species, fertilization and/or embryological development of sea urchins is inhibited.

Chemical analyses provide additional information and aid in the interpretation of the toxicity test results. For the current study, chemical analyses were performed for the measurement of porewater concentrations of several heavy metals associated with copper mining activities.

Pore waters for toxicological and chemical analyses were collected at several stations on the coast of Marinduque, near the mouths of the Boac and Mogpog rivers, and near the causeways formed by mine tailings disposal. Porewater samples were also collected at the Tres Reyes Marine Reserve, so that these non-contaminated samples could serve as a reference for test performance.

Sea urchin embryological development and fertilization were only significantly impaired by two porewater samples, suggesting the presence of contaminants in toxic amounts at those stations. The toxic samples were collected near the up current side of the Calancan (Marcopper) mine tailings causeway (stations 2 and 3 - see figure 10). The pore water from station 2 also had the highest levels of heavy metals, particularly cadmium, cobalt, copper, nickel, lead and zinc (Table 5). The concentrations of cobalt, nickel and zinc were also elevated 
at station 3. Copper concentrations were also elevated at the two river mouth stations (8 and 9) and near the CMI tailings causeway (station 7).

Visual observations also indicated biological degradation due to heavy siltation and smothered coral at a gradient off the Calancan causeway, suggesting that siltation might also be causing a physical impact.

This preliminary survey suggests that effects related to past mining activities are still evident and warrant a more comprehensive study to assess their severity and areal extent.

\section{Introduction}

In May 2000 a team of environmental and health scientists from the U.S. Geological Survey (USGS) and the U.S. Armed Forces Institute of Pathology (USAFIP) visited the Island of Marinduque, Philippines, for an overview of environmental problems created by a 1996 tailings spill from the Marcopper open-pit copper mine. As a follow-up of that initial overview, USGS and TAMU-CC scientists visited Marinduque in October 2000, with the objective of collecting environmental samples for a preliminary assessment of potential impacts of mining-related activities on the marine environment. Like the previous visit, in May 2000, the marine assessment visit was at the invitation of Philippine Congressman Edmund O. Reyes.

In this report we present the results of sediment porewater toxicity tests and chemical analyses. However, due to the limited number of samples, the results presented in this report should be considered preliminary. A more extensive survey is recommended, particularly in the areas where elevated levels of heavy metals and toxic samples were collected, in order to assess the spatial extent of the affected areas.

\section{Summary of potential environmental concerns due to mining-related activities in Marinduque's marine environment}

Impact of mine-tailings spill on the biota at the mouth of the Mogpog and Boac rivers

Concern with metals contamination at the mouth of the Boac and Mogpog rivers was expressed by the staff of Congressman Edmund Reyes and Governor of Marinduque, Carmencita Reyes, due to the transport of mine-tailings down river and into the estuarine and marine environments off the mouths of these rivers. Porewater samples were collected at these sites to assess potential biological effects.

\section{Impact of mine-tailings causeways on} surrounding environment

Two mine tailings causeways extend into the ocean on Marinduque Island (Fig. 1). One of these has been built with tailings from the CMI copper mine, which operated in the 1970's. The other one, more recent and located in Calancan Bay, is composed of

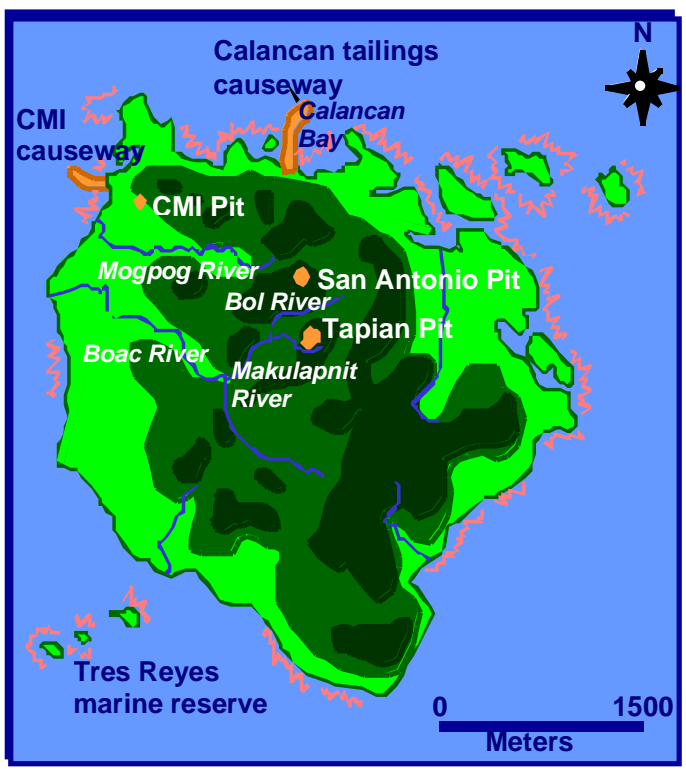

Figure 1. Map of Marinduque showing mine-tailings causeways 
mine tailings from the Marcopper Mine deposited from 1975 through 1990. Both are cause for concern because of the possibility of copper leachates spreading throughout the surrounding marine waters and sediments.

\section{USGS - TAMU-CC October, 2000 Trip Objectives}

Based on the information gathered by a team of USGS and USAFIP environmental and health scientists on a previous trip (Plumlee et al. 2000), a second trip to Marinduque was undertaken by marine ecotoxicologists, Drs. R. Scott Carr (USGS) and Marion Nipper (TAMU-CC), with the purpose of assessing the bioavailability and potential environmental impact of contaminants introduced into the marine environment by copper mining activities on the island. A meeting with local citizens and administrators also allowed the presentation of information on our activities and their objectives (Fig. 2).

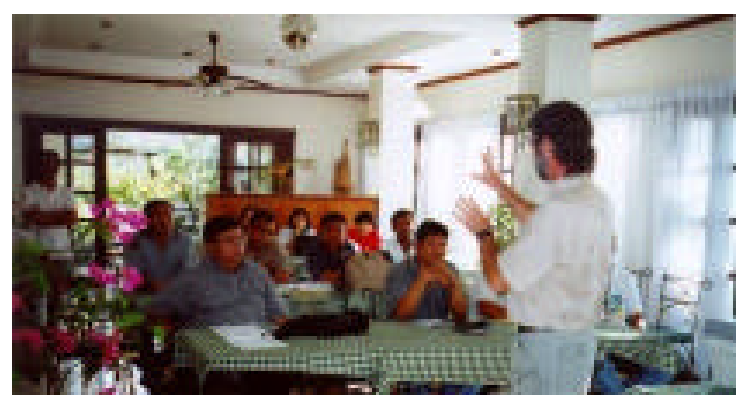

Figure 2. Dr. Scott Carr discussing the objectives of our field trip on Marinduque to the local community, including representatives of non-government organizations, church and city administration.

USGS - TAMU-CC October, 2000 Trip Itinerary and Observations

October 13 (Friday)
- Flew into Manila, arriving in the evening, and met with Congressman Edmund O. Reyes and Governor Carmencita Reyes. Took ferry to Marinduque later that night, arriving on the morning of the next day.

\section{October 14 (Saturday)}

- Were received by the Governor's staff, including Dindo Asuncion, Joven Lilles Ton Monteagudo, and colleagues, who accompanied us at all times during our stay in Marinduque and provided for all the field trip-related needs.

- After a brief stop at the hotel for breakfast, an exploratory field trip was undertaken, with guidance of the Marinduque field team, for the inspection of potential sampling sites and analysis of local maps. During this initial field trip the following sites were visited: mouths of the Boac and Mogpog rivers, and the two mine tailings causeways protruding into the ocean at Calancan Bay (Marcopper) and North of the Mogpog River (CMI). We returned to those sites on the next days to collect sediments and/or pore waters. All sampling sites are presented on Figure 3 .

\section{October 15 (Sunday)}

- Collected samples from six selected stations in the vicinity of the Marcopper mine tailings causeway (Fig. 4), Calancan Bay, to analyze the spatial extent of contamination and biological effects, if any (Fig. 3 - Stations 1-6).

\section{October 16 (Monday)}

- Collected samples from 3 stations: Northern side of the CMI mine tailings causeway (Fig. 5) (Station 7 on Fig. 3); mouth of the Mogpog River (Fig. 6, 
Station 8 on Fig. 3); and mouth of the Boac River (Fig. 7; Station 9 on Fig. 3).

\section{October 17 (Tuesday)}

- Collected samples from three reference sites off Gaspar Island, in the marine sanctuary of Tres Reyes, distant from pollution sources (Fig. 8).

- Met with local citizens, including representatives from NGOs, the city administration and the church.

\section{October 18 (Wednesday)}

- Flew back to Manila, conditioned

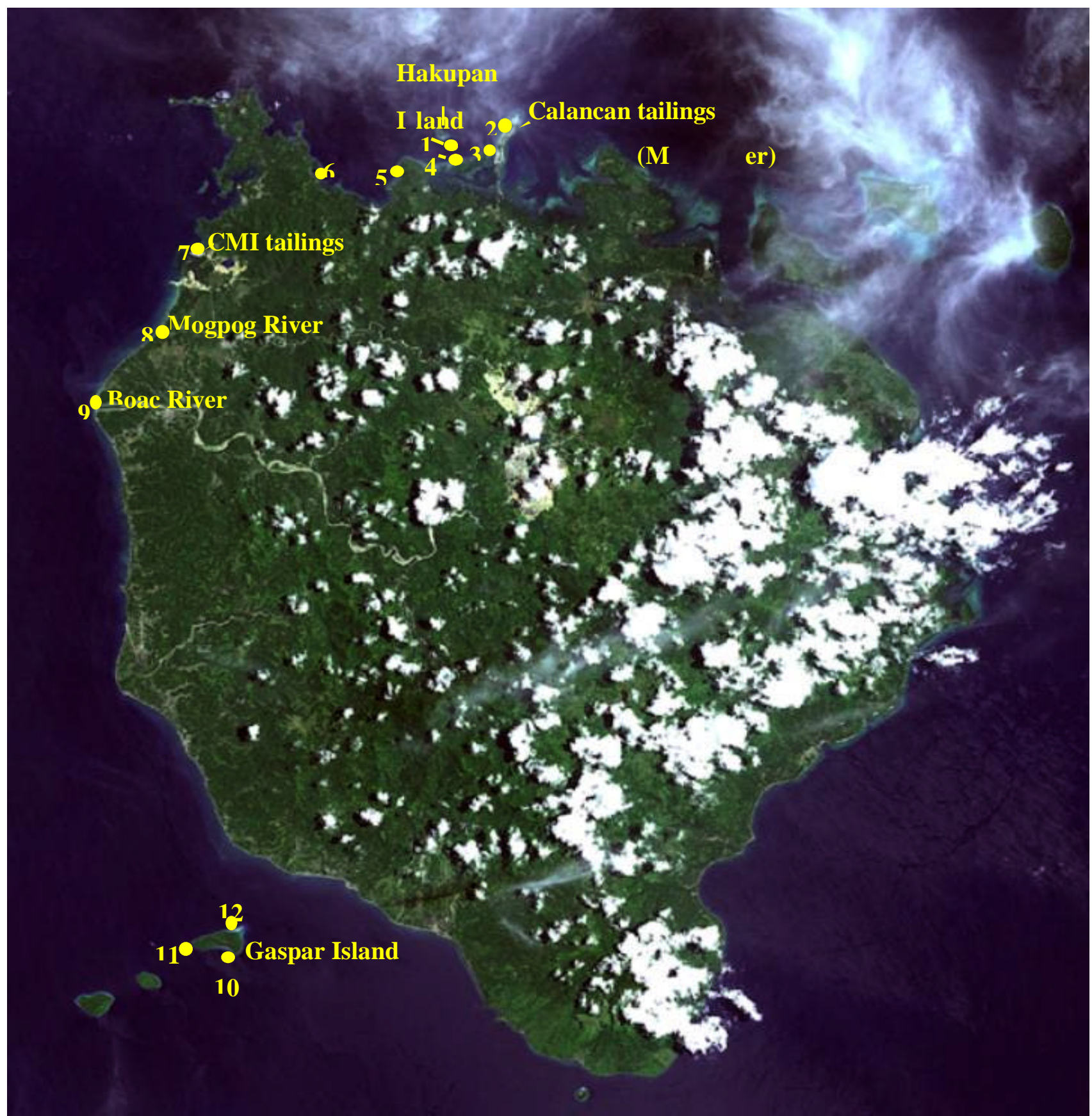

Figure 3. Satellite view of Marinduque Island with sampling stations (Landsat image taken in August 2000). 
collected porewater and overlying water samples in a cooler with dry ice and sediment samples in a cooler with blue ice, and shipped them by Federal Express to the laboratory in the USA.

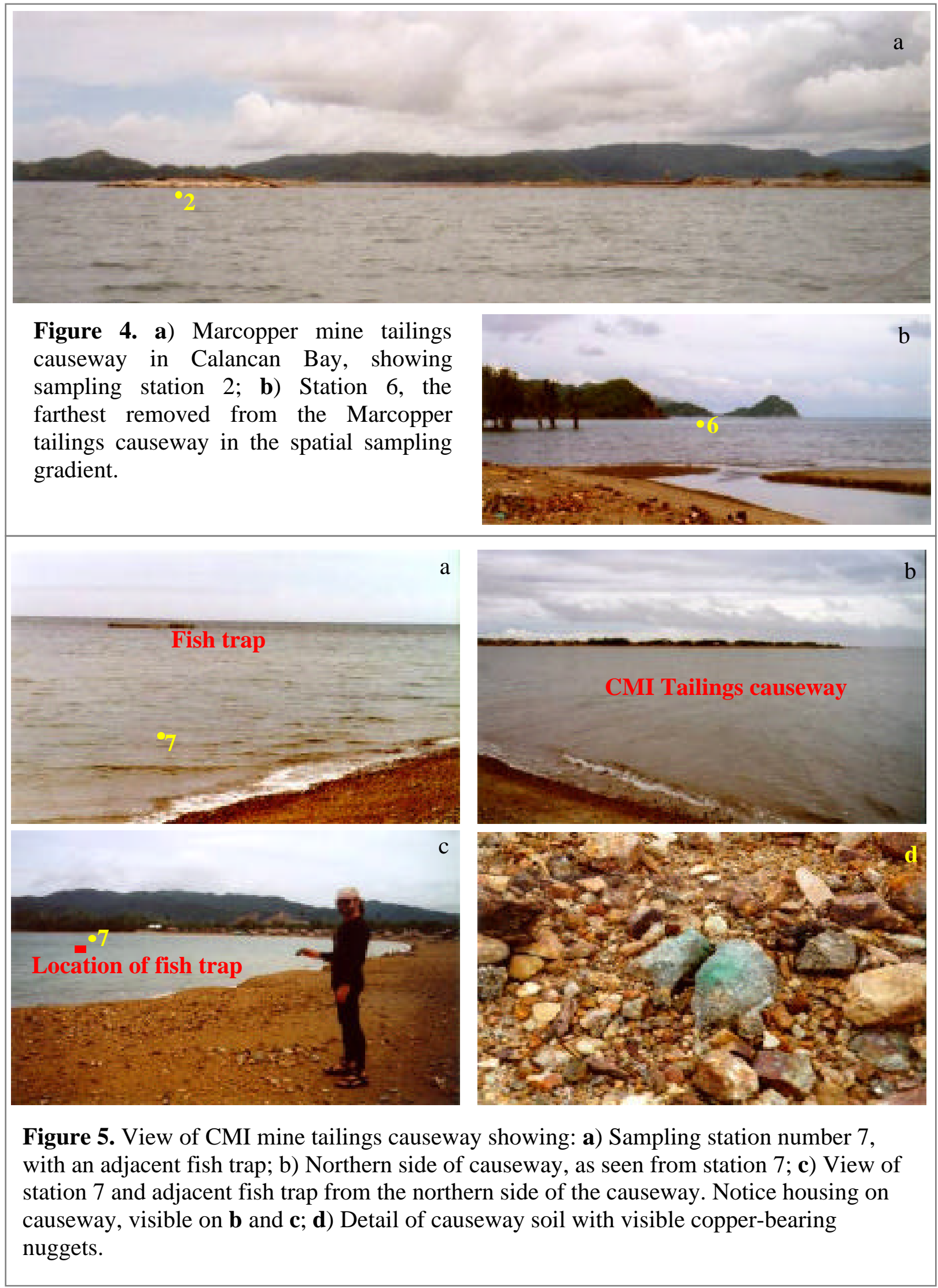




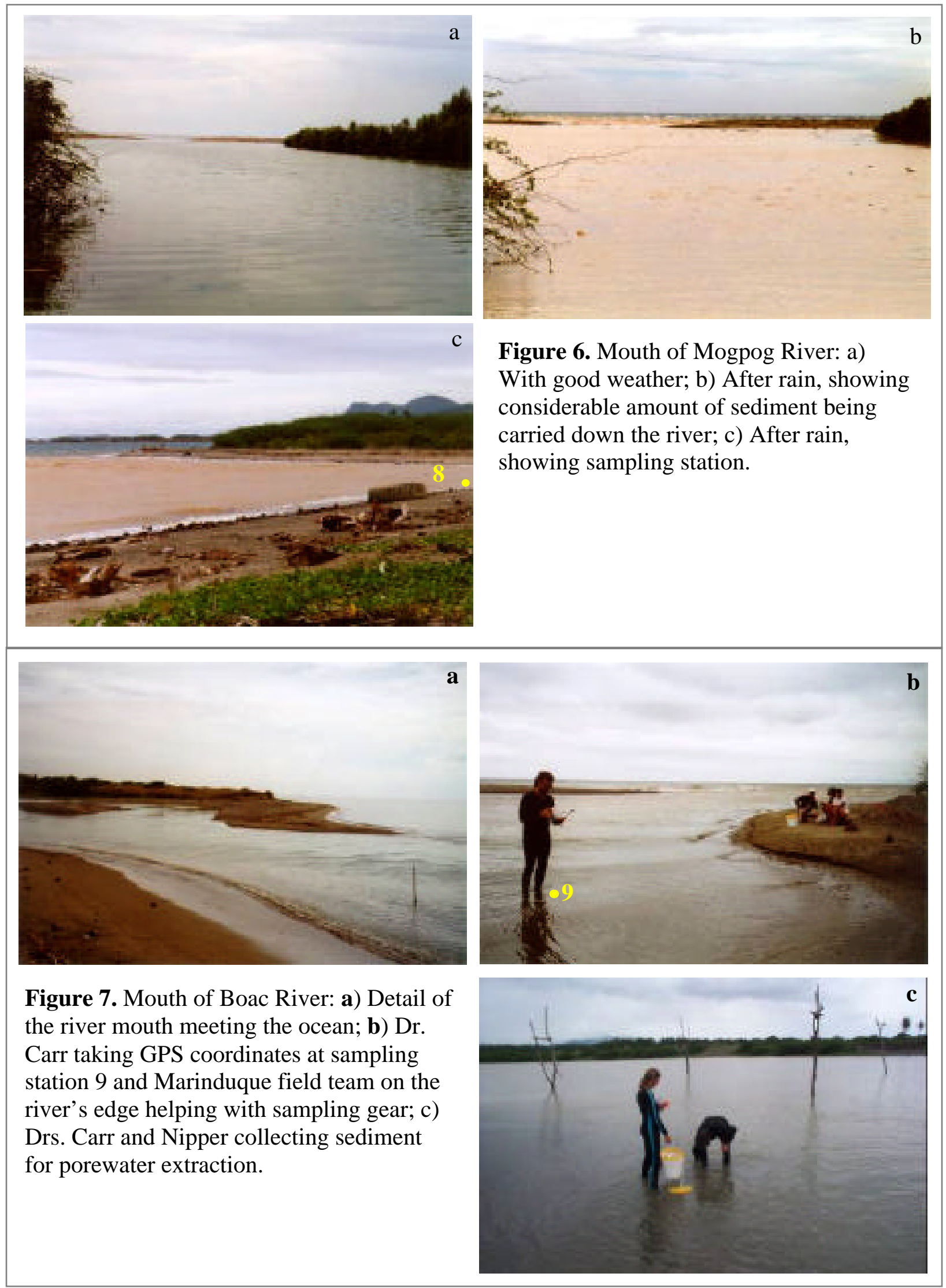




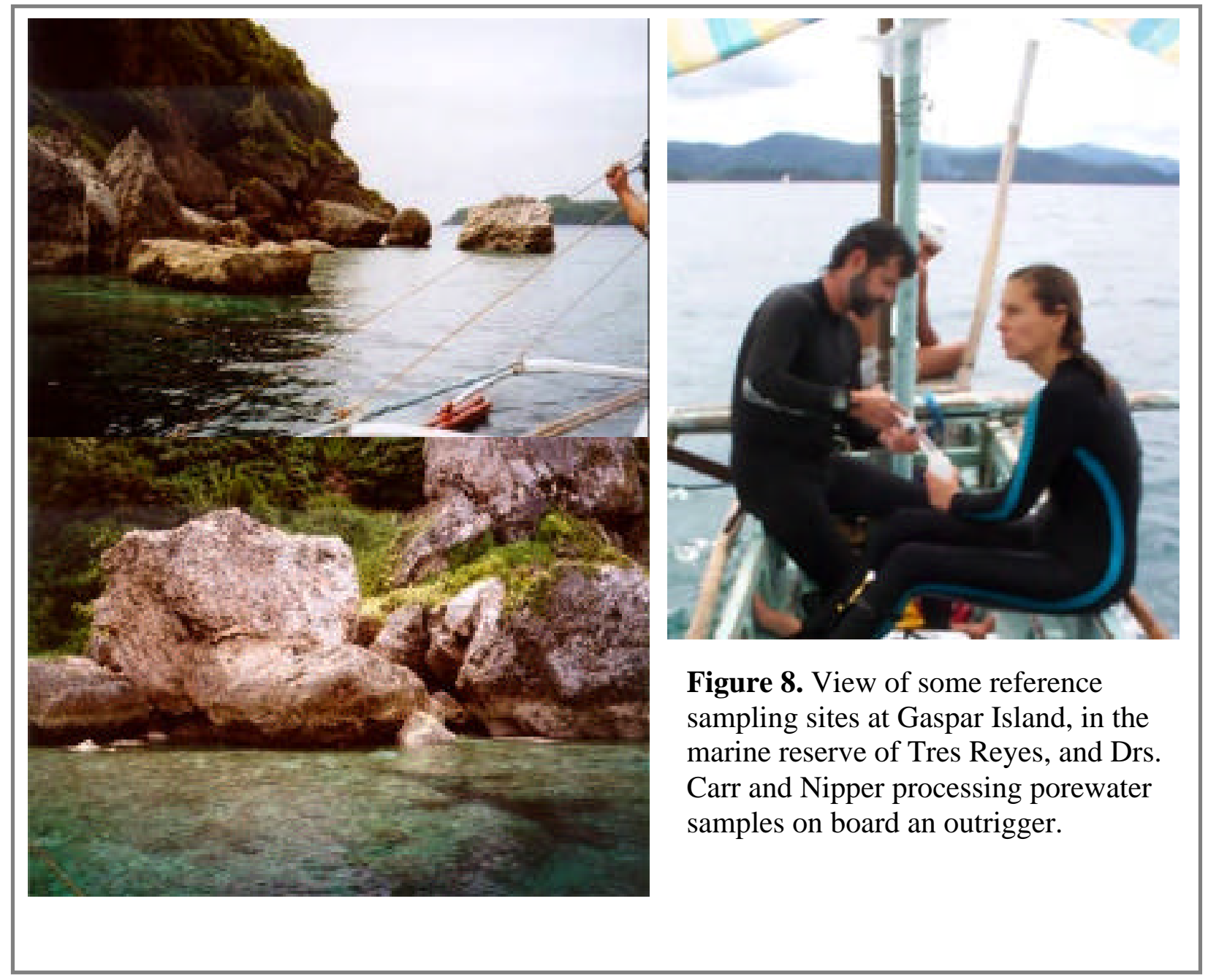

\section{Materials and Methods}

Sampling sites and collection methods

Pore water and/or sediment and overlying water samples were collected from 12 stations off Marinduque Island (Fig. 3) in October 2000. Sampling site designation, details and coordinates are presented in Table 1. Sediment samples and water overlying the sediment surface were collected at several stations (Table 1) for chemical analyses. Pore water for toxicity testing and chemical analyses was collected in situ, by divers, at stations 1-6 and 10-12. Weather and sea conditions did not permit in situ sampling by diving at stations 7,8 and 9. Therefore, sediment cores were collected at knee depth at these three stations and pore water was extracted on shore.

Sediment and overlying water were collected directly into pre-cleaned $250 \mathrm{ml}$ high-density polyethylene containers with screw caps and kept on ice for up to three days, until arrival in Manila and shipping to the USA. Pore water was extracted by vacuum, using a device that consisted of a ground glass aquarium air stone as the filtration medium, attached to a 60-ml high density polyethylene syringe (Fig. 9). All sampling material was pre-soaked in distilled water for a minimum of 24 hours prior to use, and syringes were acid-washed. Samples were removed from the syringes and placed in pre-cleaned $500 \mathrm{ml}$ high- 
density polyethylene containers, and kept in coolers on ice until arrival at the hotel. Porewater samples were then filtered through acid washed, binder free borosilicate glass fiber filters with pore size of $0.7 \mu \mathrm{m}$. Samples to be used for toxicity testing were placed in pre-cleaned $250 \mathrm{ml}$ high density polyethylene jars with Teflon ${ }^{\circledR}$ lined screw caps, and an aliquot of the filtered pore waters for chemical analyses was placed in $50 \mathrm{ml}$ high density polyethylene containers. The filters used for porewater filtration were of the kind routinely used in chemistry laboratories for the filtration of samples to be analyzed for metals. These filters may have removed other categories of contaminants from the samples, if they were present, but since the present survey was conducted to determine environmental effects caused by metals contamination from the mine tailings, removal of other contaminants by the filtration procedure was deemed acceptable. Filtered samples were kept in coolers on ice for up to 3 days, until arrival in Manila, whereupon they were shipped to the USA by Federal Express, accompanied by sample tracking sheets. Water samples for toxicity testing were shipped on dry ice, whereas water and sediment samples for chemical analyses were shipped on blue ice. Upon arrival at the USGS toxicity testing laboratory in Corpus Christi, Texas, the samples were logged into the laboratory sample tracking systems. The samples for toxicity testing were placed in a freezer at $20^{\circ} \mathrm{C}$, and those for chemical analyses were shipped on blue ice to the USGS chemistry laboratory in Denver, Colorado.

Table 1. Description of sampling sites and related information

\begin{tabular}{|c|c|c|c|c|c|}
\hline $\begin{array}{l}\text { Site } \\
\text { No. }\end{array}$ & $\begin{array}{c}\text { Site } \\
\text { Designation }\end{array}$ & Latitude/Longitude & Site Description & $\begin{array}{l}\text { Depth } \\
(\mathbf{m})\end{array}$ & $\begin{array}{l}\text { Type of sample } \\
\text { collected }\end{array}$ \\
\hline 1 & $\begin{array}{l}\text { Hakupan } \\
\text { Island }\end{array}$ & $\begin{array}{l}13 \rrbracket 33.08 \mathrm{~N} / 121 \rrbracket 56.66 \\
\mathrm{E}\end{array}$ & $\sim 200 \mathrm{~m} \mathrm{~S}$ of Hakupan Island & 15.0 & Pore water $(\mathrm{PW})$ \\
\hline 2 & $\begin{array}{l}\text { Calancan } \\
\text { Causeway }\end{array}$ & $\begin{array}{l}13 \varsubsetneqq 33.70 \mathrm{~N} / 121 \rrbracket 58.30 \\
\mathrm{E}\end{array}$ & $\begin{array}{l}\text { 200 m W of tip of Calancan } \\
\text { Causeway }\end{array}$ & 2.0 & $\begin{array}{l}\text { PW, sediment }(\mathrm{S}) \text {, } \\
\text { overlying water }(\mathrm{OW})\end{array}$ \\
\hline 3 & $\begin{array}{l}\text { Calancan } \\
\text { Cove }\end{array}$ & $\begin{array}{l}13 \rrbracket 32.84 \mathrm{~N} / 121 \rrbracket 57.58 \\
\mathrm{E}\end{array}$ & $\begin{array}{l}\sim 200 \mathrm{~m} \mathrm{~W} \text { of Calancan } \\
\text { Causeway and } \sim 400 \mathrm{~m} \mathrm{~N} \text { of } \\
\text { mainland }\end{array}$ & 7.5 & PW \\
\hline 4 & Botilao & $\begin{array}{l}13 \varpi 32.65 N / 121 \rrbracket 56.20 \\
E\end{array}$ & $\begin{array}{l}\text { 300 } \mathrm{m} \mathrm{N} \text { of mainland and } \\
\text { directly } \mathrm{S} \text { of Hakupan Island }\end{array}$ & 9.0 & PW \\
\hline 5 & Dinahunan & $\begin{array}{l}13 \varpi 32.26 \mathrm{~N} / 121 \rrbracket 55.62 \\
\mathrm{E}\end{array}$ & $\begin{array}{l}\sim 300 \mathrm{~m} \mathrm{~W} \text { of shore and } \sim 500 \\
\mathrm{NW} \text { of oil tank and pier }\end{array}$ & 6.5 & PW \\
\hline 6 & Guisian & $\begin{array}{l}13 \rrbracket 32.83 \mathrm{~N} / 121 \rrbracket 53.56 \\
\mathrm{E}\end{array}$ & $\begin{array}{l}100 \mathrm{~m} \text { from shore - } \\
\text { believed to be "unimpacted" } \\
\text { area in aerial photo (Fig. } 11 \\
\text { in Plumlee et al., 2000) }\end{array}$ & 7.6 & PW, S, OW \\
\hline 7 & $\begin{array}{l}\text { CMI } \\
\text { Causeway }\end{array}$ & $\begin{array}{l}13 \varpi 30.04 N / 121 \oslash 50.66 \\
E\end{array}$ & $\begin{array}{l}\sim 200 \mathrm{~m} \mathrm{~N} \text { of CMI causeway, } \\
\sim 20 \mathrm{~m} \text { from shore }\end{array}$ & 1.5 & $\mathrm{PW}, \mathrm{S}$ \\
\hline 8 & Mogpog River & $\begin{array}{l}13 \fallingdotseq 29.05 N / 121 \oslash 50.31 \\
E\end{array}$ & South side of river mouth & 0.5 & $\mathrm{PW}, \mathrm{S}$ \\
\hline 9 & Boac River & $\begin{array}{l}13 \varpi 27.04 \mathrm{~N} / 121 \varpi 48.70 \\
\mathrm{E}\end{array}$ & $\begin{array}{l}\text { North side of mouth of } \\
\text { northern tributary }\end{array}$ & 0.2 & PW \\
\hline 10 & $\begin{array}{l}\text { Gaspar Island- } \\
\text { south }\end{array}$ & $\begin{array}{l}13 \fallingdotseq 14.72 \mathrm{~N} / 121 \oslash 51.82 \\
\mathrm{E}\end{array}$ & $\begin{array}{l}\text { South side of Gaspar Island } \\
\sim 50 \mathrm{~m} \text { from shore }\end{array}$ & 12.0 & PW \\
\hline 11 & $\begin{array}{l}\text { Gaspar Island- } \\
\text { west }\end{array}$ & $\begin{array}{l}13 \rrbracket 14.95 \mathrm{~N} / 121 \rrbracket 50.95 \\
\mathrm{E}\end{array}$ & $\begin{array}{l}\text { West side of Gaspar Island } \\
\sim 50 \mathrm{~m} \text { from shore }\end{array}$ & 12.0 & $\mathrm{PW}, \mathrm{S}, \mathrm{OW}$ \\
\hline 12 & $\begin{array}{l}\text { Gaspar Island- } \\
\text { north }\end{array}$ & $\begin{array}{l}13 \varpi 15.20 \mathrm{~N} / 121 \rrbracket 51.67 \\
\mathrm{E}\end{array}$ & $\begin{array}{l}\text { North side of Gaspar Island } \\
\sim 50 \mathrm{~m} \text { from shore }\end{array}$ & 12.0 & PW \\
\hline
\end{tabular}




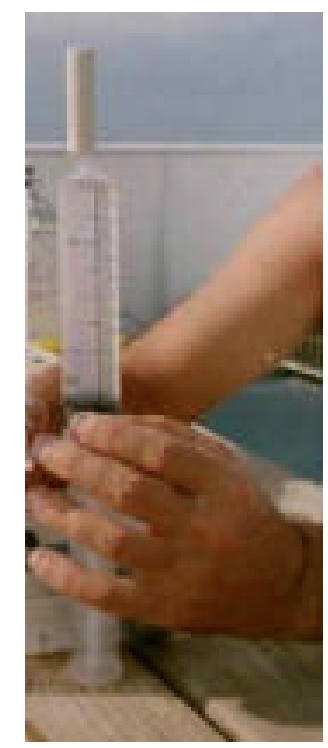

Figure 9. Porewater sampling device

\section{Porewater Quality Measurement and Adjustment}

Two days before conducting the toxicity tests, the samples were moved from the freezer to a refrigerator at $4^{\circ} \mathrm{C}$. One day prior to testing samples were thawed in a tepid $\left(20^{\circ} \mathrm{C}\right)$ water bath. Temperature of the samples was maintained at $20 \pm 1^{\circ} \mathrm{C}$. Sample salinity was measured and adjusted to $30 \pm 1 \%$ using purified deionized water or concentrated brine (see SOP F10.12, Appendix 1). Other water quality measurements (dissolved oxygen, $\mathrm{pH}$, sulfide, and ammonia concentration) were made. Dissolved oxygen (DO) was measured with an $\mathrm{YSI}^{\circledR}$ meter, salinity was measured with a Reichert ${ }^{\circledR}$ refractometer, and $\mathrm{pH}$, and total ammonia (expressed as nitrogen; $\mathrm{NH}_{4}$ ) were measured with an Orion $^{\circledR}$ meter and the respective probes. Unionized ammonia (expressed as nitrogen; $\mathrm{NH}_{3}$ ) concentrations were calculated for each sample using the respective salinity, temperature, $\mathrm{pH}$, and $\mathrm{NH}_{4}$ values. Following water quality measurements and adjustments, the samples were stored overnight at $4^{\circ} \mathrm{C}$ but returned to $20 \pm 1^{\circ} \mathrm{C}$ before the start of the toxicity tests.
Toxicity Testing with Sea Urchin Gametes and Embryos

Toxicity of the pore water was determined using the fertilization and embryological development tests with the sea urchin Arbacia punctulata following the procedures outlined in SOP F10.6 and F10.7 (Appendices 2 and 3).

Arbacia punctulata urchins used in this study were obtained from Gulf Specimen Company, Inc. (Panacea, Florida). A standard reference porewater sample collected from Redfish Bay, Texas, which had been extracted by pneumatic pressure and thereafter handled identically to the test samples, was included with the toxicity tests as a negative control, in addition to the reference samples from Gaspar Island, Philippines. The standard site for reference porewater collection in Redfish Bay is far removed from any known sources of contamination and has been used extensively as a reference site (Carr and Chapman, 1992; National Biological Survey, 1993, 1994; National Biological Service 1995a, b; Carr et al., 1996a, b, 2000; U.S. Geological Survey, 1997, 1998, 1999; Nipper and Carr, 2001). In addition, dilution blanks of filtered seawater and brine controls (purified deionized water with brine added to reach a $30 \%$ salinity) were also included. A dilution series test with a reference toxicant, sodium dodecyl sulfate (SDS), was included as a positive control. Reference toxicant test results were compared to a control chart with the results of the previous tests with this reference toxicant, in order to ensure that the sensitivity of the test organisms was within the standard range (Environment Canada, 1990).

\section{Toxicity Test Data Analysis}

The standard statistical analyses for these toxicity tests involve comparisons among treatments using ANOVA and 
Dunnett's test. Prior to statistical analysis, the transformed data sets were screened for outliers (SAS Institute Inc., 1992) by comparing the studentized residuals to a critical value from a $t$-distribution chosen using a Bonferroni-type adjustment. The adjustment is based on the number of observations, $n$, so that the overall probability of a type I error is at most 5\%. The critical value, $c v$, is given by the following equation: $c v=t\left(\mathrm{df}_{\text {Error }}, .05 /(2 \mathrm{x}\right.$ $n)$ ). No outliers were detected. The transformed data sets were tested for normality and for homogeneity of variance using SAS/LAB ${ }^{\circledR}$ Software (SAS Institute Inc., 1992). Reference toxicant test results were analyzed by the trimmed SpearmanKarber method (Hamilton et al., 1977) with Abbott's correction (Morgan, 1992) to calculate $\mathrm{EC}_{50}$ (effective concentration to $50 \%$ of the test organisms) values.

A second criterion was also applied to compare test means to reference means. Detectable significance criteria (DSC) were developed to determine the $95 \%$ confidence value based on power analysis of all similar tests performed by our laboratory (Carr and Biedenbach, 1999). This value is the percent minimum difference from the reference that is necessary to detect a significant effect while minimizing type I errors. The DSC value for the sea urchin fertilization assay is $15.5 \%$ at $\&$ \& 0.05 , and $19 \%$ at \& 0.01 . For the embryological development test the DSC values at \& 0.05 and \& 0.01 are 16.4 and $20.6 \%$, respectively.

\section{Chemical analyses of pore waters and sediments}

Pore waters were analyzed for major cations and selected trace metals and metalloids using inductively coupled plasma-mass spectrometry. A detailed description of the methods applied for the chemical analyses and quality assurance procedures is described in Lamothe et al. (1999). It is believed that chloride interference with the copper analyses caused an increase of approximately $10 \mu \mathrm{g} / \mathrm{L}$ in the measured concentrations. Therefore, this was accounted for in the interpretation of results. However, the copper values measured at stations 8 and 9 are expected to be accurate due to their low salinity (Table $2)$, thus lacking chloride interference.

\section{Results and Discussion}

\section{Pore Water Quality Measurements}

Water quality measurements for all porewater samples, including the reference pore water from Redfish Bay, Texas, as well as the $0.45 \mu \mathrm{m}$ filtered seawater control, are presented on Table 2. Salinity was the most variable of the measured porewater quality parameters, ranging from 2 to $38 \mathrm{ppt}$. All samples required salinity adjustment prior to toxicity testing in order to satisfy the test salinity requirement of $30 \pm 1$ ppt. The percentage of pore water in the original test samples (\%OS) after salinity adjustment (Table 2) ranged from 75 to $96 \%$. Dissolved oxygen was above $80 \%$ saturation in all samples, and $\mathrm{pH}$ ranged from 7.43 and 8.25. Unionized ammonia $\left(\mathrm{NH}_{3}\right)$ was less than 5.4 $\mu \mathrm{g} / \mathrm{L}$ in all samples from Marinduque. The Redfish Bay reference pore water had a somewhat higher $\mathrm{pH}$ (8.38), as well as higher $\mathrm{NH}_{3}$ concentration, of $57.8 \mu \mathrm{g} / \mathrm{L}$, which is still below toxic levels to $A$. punctulata fertilization and embryological development (Carr et al., 1996a).

\section{Sea Urchin Toxicity Tests}

Raw data and means from the fertilization test are given in Table 3, and for the embryological development test, in Table 4. Only the two porewater samples nearest to the Calancan mine tailings causeway were significantly toxic to sea urchin (A. punctulata) early-life stages. The 
sample from station 2, closest to the causeway, was the most toxic overall, causing significant adverse effects in both tests even at a dilution of $25 \%$, whereas the sample from station 3 was toxic in both tests at the $50 \%$ dilution (see Fig. 10). The gradient sampling performed in the area of the Calancan causeway was in the predominately up-current direction. Based on the toxicity of the two samples collected closest to the causeway, it is likely that environmental effects caused by the tailings would be more widespread in the downcurrent direction. The $\mathrm{EC}_{50}$ values for the SDS tests (Tables 3 and 4) were within the normal range based on the control chart with the results of previous tests performed in our laboratory with this reference toxicant, indicating that the sensitivity of the test organisms was within the acceptable standard.

In previous surveys, pore water from sandy sediment collected in the vicinity of coral reefs in southeastern Mexico and in
Honolulu, Hawaii, exhibited toxicity, showing that these kinds of tests are useful indicators of contaminant accumulation in toxic amounts around coral reefs, and could serve as early warning signals of potential biological effects to the reef itself (Nipper and Carr, 2001). The results obtained in the current study suggest that the area adjacent to the Calancan causeway is adversely affected by the mine tailings disposal. Visual observations at the sites also indicated biological degradation, with only one species of small fish observed at station 2 and heavy siltation and smothered coral seen at station 3 (see next section). Pore water from stations 4 and 5 was not toxic to sea urchin early life stages, but a large amount of silt covering corals was still observed at those sites, suggesting that although there was no evidence of biological degradation caused by chemical contamination, a physical impact might be caused by siltation due to erosion of fine particulate matter from land.

Table 2. Water quality measurements of samples used for toxicity testing

\begin{tabular}{|c|c|c|c|c|c|c|c|c|c|}
\hline Sample & $\begin{array}{c}\text { Original } \\
\text { Salinity } \\
\text { (ppt) }\end{array}$ & $\begin{array}{c}\text { Adjusted } \\
\text { Salinity } \\
(\mathbf{p p t})\end{array}$ & $\begin{array}{c}\text { OUS }^{1} \\
(\%) \\
\end{array}$ & $\begin{array}{c}\mathrm{DO}^{2} \\
(\mathrm{mg} / \mathrm{L}) \\
\end{array}$ & $\begin{array}{c}\text { DO } \\
\text { \% sat } \\
\end{array}$ & pH & $\begin{array}{l}\mathrm{NH}_{4}{ }^{3} \\
(\mathrm{mg} / \mathrm{L}) \\
\end{array}$ & $\begin{array}{l}\mathrm{NH}_{3}{ }^{4} \\
(\mu \mathrm{g} / \mathrm{L}) \\
\end{array}$ & $\begin{array}{l}\text { Sulfide } \\
(\mathrm{mg} / \mathrm{L}) \\
\end{array}$ \\
\hline Redfish Bay Ref. & 40 & 30 & 75 & 6.69 & 90.7 & 8.38 & 0.803 & 57.8 & $<0.01$ \\
\hline 1 & 34.5 & 30 & 88 & 6.67 & 90.2 & 7.61 & $<0.1$ & $<1.3$ & $<0.01$ \\
\hline 2 & 34 & 30 & 88 & 6.93 & 93.1 & 7.52 & $<0.1$ & $<1.1$ & $<0.01$ \\
\hline 3 & 38 & 30 & 75 & 7.15 & 95.9 & 7.49 & $<0.1$ & $<1.1$ & $<0.01$ \\
\hline 4 & 26 & 30 & 96 & 6.79 & 91.9 & 7.72 & $<0.1$ & $<1.7$ & $<0.01$ \\
\hline 5 & 34 & 30 & 88 & 6.86 & 92.2 & 7.550 & $<0.1$ & $<1.1$ & $<0.01$ \\
\hline 6 & 35 & 30 & 86 & 6.87 & 92.3 & 7.43 & $<0.1$ & $<0.9$ & $<0.01$ \\
\hline 7 & 32 & 30 & 94 & 6.92 & 92.8 & 7.60 & 0.137 & 1.7 & $<0.01$ \\
\hline 8 & 2 & 30 & 75 & 7.00 & 94.00 & 8.25 & $<0.1$ & $<5.4$ & $<0.01$ \\
\hline 9 & 2 & 30 & 75 & 6.94 & 92.9 & 8.09 & $<0.1$ & $<3.8$ & $<0.01$ \\
\hline 10 & 35 & 30 & 87 & 6.75 & 91.0 & 8.05 & $<0.1$ & $<3.5$ & $<0.01$ \\
\hline 11 & 35 & 30 & 87 & 6.87 & 92.5 & 7.51 & 0.119 & 1.2 & $<0.01$ \\
\hline 12 & 35 & 30 & 86 & 6.77 & 90.9 & 7.49 & $<0.1$ & $<1.0$ & $<0.01$ \\
\hline Brine control & 0 & 30 & 75 & 6.36 & 87.8 & 8.41 & $<0.1$ & $<7.7$ & $<0.01$ \\
\hline
\end{tabular}

${ }^{1}$ Percent of original undiluted sample after salinity adjustment; ${ }^{2}$ Dissolved oxygen; ${ }^{3}$ Total ammonia;

${ }^{4}$ Unionized ammonia. 


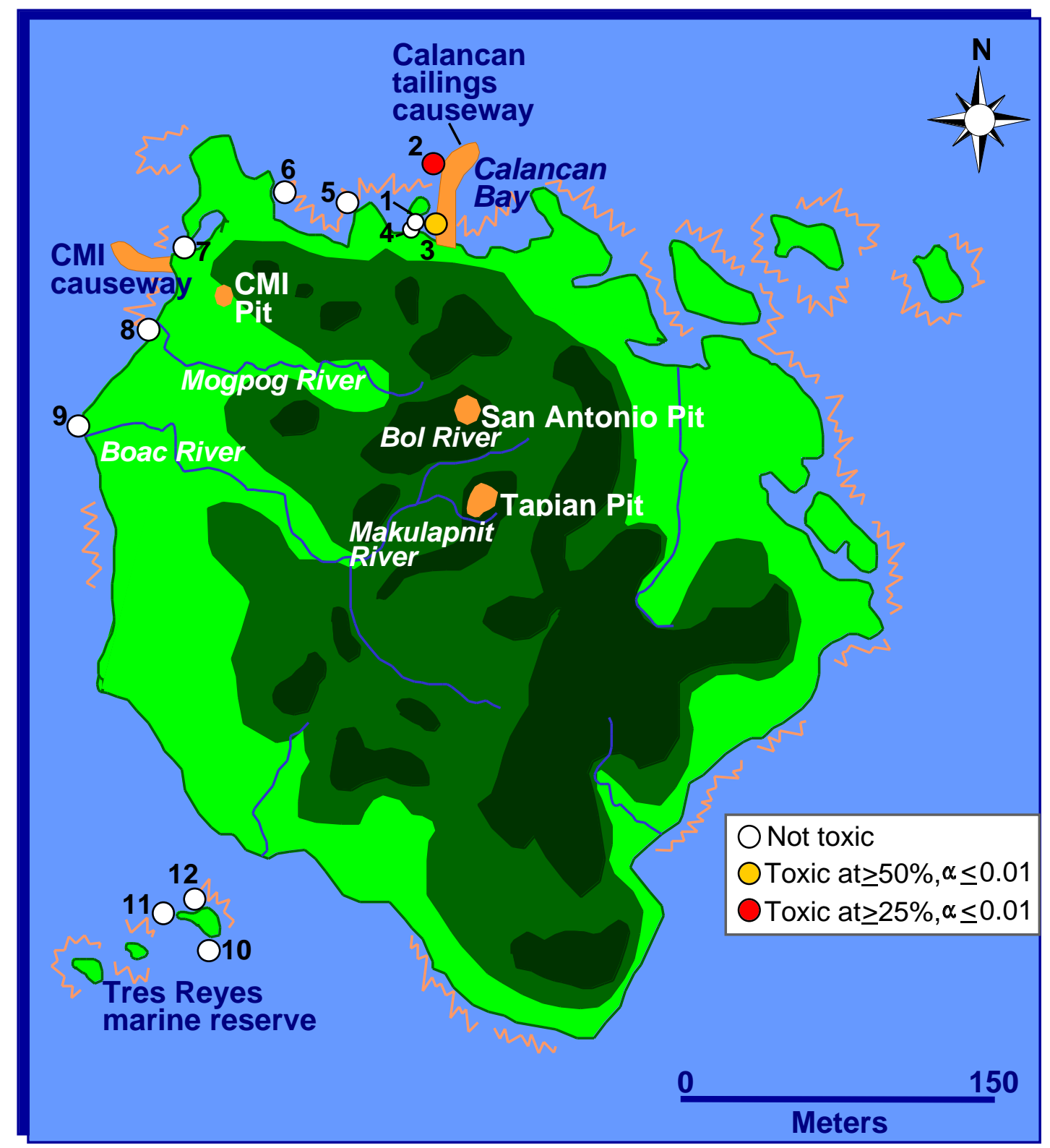

Figure 10. Map of Marinduque showing porewater toxicity data for sea urchin fertilization and embryological development. 
Table 3. Mean $(n=5)$ percent fertilization of the sea urchin, A. punctulata, in porewater samples from Marinduque, reference and control samples, and in the reference toxicant test with SDS

\begin{tabular}{|c|c|c|c|c|c|}
\hline Sample & $\%$ Dilution & $\begin{array}{c}\text { Mean Fert. } \\
(\%)\end{array}$ & $\begin{array}{l}\text { Standard } \\
\text { Deviation }\end{array}$ & $\begin{array}{c}\mathrm{EC}_{50} \\
(95 \% \mathrm{CI})^{1}\end{array}$ & $\begin{array}{c}\text { Significant } \\
\text { Effect }^{2}\end{array}$ \\
\hline Redfish Bay & 100 & 99.6 & 0.70 & & \\
\hline Redfish Bay & 50 & 99.8 & 0.42 & & \\
\hline Redfish Bay & 25 & 99.8 & 0.42 & & \\
\hline 1 & 100 & 99.0 & 0.71 & & \\
\hline 1 & 50 & 98.6 & 1.67 & $>100$ & \\
\hline 1 & 25 & 98.6 & 0.55 & & \\
\hline 2 & 100 & 0.8 & 1.30 & & $* *$ \\
\hline 2 & 50 & 0.2 & 0.45 & $<25$ & $* *$ \\
\hline 2 & 25 & 0.2 & 0.45 & & $* *$ \\
\hline 3 & 100 & 19.6 & 4.39 & & $* *$ \\
\hline 3 & 50 & 52.8 & 8.47 & 53.45 & $* *$ \\
\hline 3 & 25 & 87.4 & 4.16 & $(46.99-60.80)$ & \\
\hline 4 & 100 & 99.4 & 0.55 & & \\
\hline 4 & 50 & 99.2 & 1.30 & $>100$ & \\
\hline 4 & 25 & 99.4 & 0.89 & & \\
\hline 5 & 100 & 100.0 & 0.00 & & \\
\hline 5 & 50 & 100.0 & 0.00 & $>100$ & \\
\hline 5 & 25 & 99.8 & 0.45 & & \\
\hline 6 & 100 & 98.2 & 1.48 & & \\
\hline 6 & 50 & 98.0 & 1.00 & $>100$ & \\
\hline 6 & 25 & 97.2 & 2.49 & & \\
\hline 7 & 100 & 96.8 & 1.48 & & \\
\hline 7 & 50 & 97.2 & 1.79 & $>100$ & \\
\hline 7 & 25 & 99.2 & 0.45 & & \\
\hline 8 & 100 & 86.4 & 6.07 & & \\
\hline 8 & 50 & 91.6 & 2.07 & $>100$ & \\
\hline 8 & 25 & 93.0 & 3.54 & & \\
\hline 9 & 100 & 100.0 & 0.00 & & \\
\hline 9 & 50 & 99.4 & 0.89 & $>100$ & \\
\hline 9 & 25 & 99.8 & 0.45 & & \\
\hline 10 & 100 & 100.0 & 0.00 & & \\
\hline 10 & 50 & 99.4 & 1.34 & $>100$ & \\
\hline 10 & 25 & 100.0 & 0.00 & & \\
\hline 11 & 100 & 98.8 & 2.68 & & \\
\hline 11 & 50 & 99.2 & 0.45 & $>100$ & \\
\hline 11 & 25 & 99.2 & 0.45 & & \\
\hline 12 & 100 & 99.4 & 0.89 & & \\
\hline 12 & 50 & 99.4 & 0.89 & $>100$ & \\
\hline 12 & 25 & 99.2 & 0.84 & & \\
\hline Seawater Contr. & 100 & 99.2 & 1.03 & & \\
\hline Brine control & 100 & 96.6 & 0.55 & & \\
\hline
\end{tabular}


Table 3. Continued

\begin{tabular}{lcccc}
\hline $\mathrm{SDS}(\mathrm{mg} / \mathrm{L})$ & 20 & 0.0 & 0.00 & \\
$\mathrm{SDS}(\mathrm{mg} / \mathrm{L})$ & 10 & 0.4 & 0.89 & \\
$\mathrm{SDS}(\mathrm{mg} / \mathrm{L})$ & 5 & 43.0 & 6.40 & 4.76 \\
$\mathrm{SDS}(\mathrm{mg} / \mathrm{L})$ & 2.5 & 100.0 & 0.00 & $(4.45-5.10)$ \\
$\mathrm{SDS}(\mathrm{mg} / \mathrm{L})$ & 1.25 & 99.8 & 0.45 & \\
\hline
\end{tabular}

${ }^{1} 95 \%$ confidence interval in parenthesis;

${ }^{2}$ Significantly different from the reference and below DSC at $\alpha \leq 0.01$.

Table 4. Mean $(n=5)$ percent normal embryological development of the sea urchin, $A$. punctulata, in porewater samples from Marinduque, reference and control samples, and in the reference toxicant test with SDS.

\begin{tabular}{|c|c|c|c|c|c|}
\hline Sample & \% Dilution & $\begin{array}{c}\text { Mean Normal } \\
\text { Larvae (\%) }\end{array}$ & $\begin{array}{l}\text { Standard } \\
\text { Deviation }\end{array}$ & $\begin{array}{c}\mathbf{E C}_{50} \\
(95 \% \mathrm{CI})^{1}\end{array}$ & $\begin{array}{c}\text { Significant } \\
\text { Effect }^{2}\end{array}$ \\
\hline Redfish Bay & 100 & 96.1 & 3.35 & & \\
\hline Redfish Bay & 50 & 97.9 & 2.13 & & \\
\hline Redfish Bay & 25 & 99.0 & 1.05 & & \\
\hline 1 & 100 & 93.2 & 2.39 & & \\
\hline 1 & 50 & 98.2 & 1.48 & $>100$ & \\
\hline 1 & 25 & 98.6 & 0.89 & & \\
\hline 2 & 100 & 0.0 & 0.00 & & ** \\
\hline 2 & 50 & 0.0 & 0.00 & $<25$ & ** \\
\hline 2 & 25 & 0.0 & 0.00 & & ** \\
\hline 3 & 100 & 0.0 & 0.00 & & ** \\
\hline 3 & 50 & 44.8 & 11.99 & 48.05 & ** \\
\hline 3 & 25 & 93.6 & 0.55 & $(44.60-51.76)$ & \\
\hline 4 & 100 & 94.0 & 1.58 & & \\
\hline 4 & 50 & 96.4 & 1.14 & $>100$ & \\
\hline 4 & 25 & 97.6 & 1.52 & & \\
\hline 5 & 100 & 96.4 & 1.34 & & \\
\hline 5 & 50 & 96.2 & 2.17 & $>100$ & \\
\hline 5 & 25 & 99.0 & 0.71 & & \\
\hline 6 & 100 & 95.6 & 1.14 & & \\
\hline 6 & 50 & 95.4 & 2.41 & $>100$ & \\
\hline 6 & 25 & 96.4 & 2.61 & & \\
\hline 7 & 100 & 94.4 & 2.30 & & \\
\hline 7 & 50 & 96.6 & 2.30 & $>100$ & \\
\hline 7 & 25 & 96.6 & 1.52 & & \\
\hline 8 & 100 & 93.2 & 2.49 & & \\
\hline 8 & 50 & 93.8 & 2.77 & $>100$ & \\
\hline 8 & 25 & 98.2 & 0.84 & & \\
\hline 9 & 100 & 96.8 & 1.64 & & \\
\hline 9 & 50 & 96.2 & 1.48 & $>100$ & \\
\hline 9 & 25 & 99.2 & 0.84 & & \\
\hline
\end{tabular}


Table 4. Continued

\begin{tabular}{ccccc}
\hline 10 & 100 & 96.2 & 2.77 & $>$ \\
10 & 50 & 95.6 & 2.30 & $>100$ \\
10 & 25 & 98.0 & 0.71 & \\
\hline 11 & 100 & 98.2 & 1.30 & $>100$ \\
11 & 50 & 98.0 & 0.71 & \\
11 & 25 & 98.2 & 1.64 & \\
\hline 12 & 100 & 94.6 & 2.07 & \\
12 & 50 & 96.2 & 1.48 & 3.46 \\
12 & 25 & 98.6 & 0.89 & $(3.38-3.55)$ \\
\hline Seawater Contr. & 100 & 97.7 & 2.41 & \\
\hline SDS (mg/L) & 20 & 0.0 & 0.00 & \\
SDS (mg/L) & 10 & 0.0 & 0.00 & \\
SDS (mg/L) & 5 & 0.2 & 0.45 & \\
SDS (mg/L) & 2.5 & 93.6 & 3.21 & \\
SDS (mg/L) & 1.25 & 98.0 & 1.87 & \\
\hline
\end{tabular}

${ }^{1} 95 \%$ confidence interval in parenthesis;

${ }^{2}$ Significantly different from the reference and below DSC at $\alpha \leq 0.01$

\section{Visual observations of sampling stations}

Station 1: Healthy appearance, with small reef patches exhibiting small stag horn coral, gorgonians, large basket sponges, crinoids, starfish, and a variety of fish.

Station 2: Coarse sand. The only visible life was one species of small burrowing fish.

Station 3: Heavy siltation, with large amount of smothered hard coral. Sabellids, crinoids and echinoids were observed, and some small reef fish were seen in the area.

Station 4: Siltation was still observed, but not as strongly as at station 3, although a large amount of coral debris was present. There were a large variety of hard corals, crinoids, starfish, nudibranch mollusks and reef fish.

Station 5: Heavy siltation and coral suffocation with only a few reef fish seen.

Station 6: Healthier appearance, with wide variety of corals, fish, and crinoids. Large groups of one species of sea urchin were observed, as well as starfish, large bivalves, basket sponges, and sabellid polychaetes.

Stations 7, 8 and 9: Sampling was performed in shallow waters without diving, for safety reasons, due to inclement weather.
Water was turbid and no visual observations were made. The sediment was mostly composed of coarse pebbles.

Stations 10, 11 and 12: These were the reference stations at the marine reserve, off Gaspar Island. They presented a healthy appearance, with large biological diversity, although little hard coral was present in the area. There were many different species of reef fish not seen at any other stations, giant clams (Tridacna sp.) and nudibranch mollusks, basket sponges, anemones and gorgonians, tunicates, crustaceans, and a variety of echinoderms, including ophiuroids and sea urchins. Six different species of sea urchins were observed at station 12 .

\section{Chemical analyses}

Chemical analyses of the porewater samples exhibited elevated concentrations of several metals at the toxic stations, particularly $\mathrm{Cd}, \mathrm{Co}, \mathrm{Cu}, \mathrm{Ni}, \mathrm{Pb}$ and $\mathrm{Zn}$ at station 2, and $\mathrm{Co}, \mathrm{Ni}$ and $\mathrm{Zn}$ at station 3 (Table 5). In a comparison of the concentrations of some selected metals with the USEPA acute and chronic saltwater criteria, it can be observed that criteria for 
copper were exceeded at stations $2,7,8$, and 9 in the vicinity of the CMI tailings causeway and at the mouth of the Mogpog river (Table 6). Acute and chronic criteria for zinc were exceeded at stations 2 and 3 , and the chronic criteria for lead and nickel were exceeded at station 2, which also had the most toxic porewater sample. Additional chemical and mineralogical analyses of sediments collected at several sites are still in progress and will be reported in subsequent publications.

Table 5. Concentration of metals in pore waters of Marinduque Island.

\begin{tabular}{|c|c|c|c|c|c|c|c|c|c|c|c|}
\hline Station & Ag & Al & Ba & Be & $\mathbf{C a}$ & Cd & Co & $\mathrm{Cr}$ & $\mathrm{Cu}^{1}$ & $\mathrm{Fe}$ & K \\
\hline & \multicolumn{3}{|c|}{$(\mu \mathrm{g} / \mathrm{L})$} & & $\mathrm{mg} / \mathrm{L}$ & \multicolumn{4}{|c|}{$(\mu \mathrm{g} / \mathrm{L})$} & & \\
\hline 1 & $<5$ & 450 & 30 & $<0.5$ & 460 & $<0.2$ & $<0.2$ & $<10$ & 10 & 890 & 460,000 \\
\hline 2 & $<5$ & 120 & 78 & $<0.5$ & 480 & 2 & 5 & $<10$ & 300 & 930 & 470,000 \\
\hline 3 & $<5$ & 56 & 62 & $<0.5$ & 500 & $<0.2$ & 3 & $<10$ & 10 & 850 & 480,000 \\
\hline 4 & $<5$ & 43 & 52 & $<0.5$ & 490 & $<0.2$ & $<0.2$ & $<10$ & 10 & 770 & 480,000 \\
\hline 5 & $<5$ & 49 & 50 & $<0.5$ & 490 & $<0.2$ & 0.4 & $<10$ & 10 & 710 & 480,000 \\
\hline 6 & $<5$ & 50 & 72 & $<0.5$ & 480 & $<0.2$ & 0.5 & $<10$ & 10 & 660 & 470,000 \\
\hline 7 & $<5$ & 74 & 72 & $<0.5$ & 450 & $<0.2$ & 0.8 & $<10$ & 20 & 620 & 410,000 \\
\hline 8 & $<5$ & 520 & 50 & $<0.5$ & 13 & $<0.2$ & $<0.2$ & $<10$ & 30 & 350 & 11,000 \\
\hline 9 & $<5$ & 170 & 40 & $<0.5$ & 41 & $<0.2$ & $<0.2$ & $<10$ & 8 & 140 & 11,000 \\
\hline 10 & $<5$ & 83 & 66 & $<0.5$ & 470 & $<0.2$ & $<0.2$ & $<10$ & 10 & 630 & 460,000 \\
\hline 11 & $<5$ & 75 & 57 & $<0.5$ & 490 & $<0.2$ & 0.4 & $<10$ & 10 & 650 & 470,000 \\
\hline 12 & $<5$ & 230 & 40 & $<0.5$ & 480 & $<0.2$ & 0.4 & $<10$ & 10 & 630 & 470,000 \\
\hline
\end{tabular}

Table 5. Continued

\begin{tabular}{|c|c|c|c|c|c|c|c|c|c|}
\hline Station & $\mathrm{Mg}$ & Mn & $\mathrm{Na}$ & $\mathrm{Ni}$ & $\mathbf{P b}$ & $\mathbf{S b}$ & $\mathrm{Tl}$ & $\mathbf{V}$ & Zn \\
\hline & $\overline{(\mathrm{mg} / \mathrm{L})}$ & $\overline{(\mu \mathrm{g} / \mathrm{L})}$ & $\overline{\mathrm{mg} / \mathrm{L}}$ & \multicolumn{5}{|c|}{$(\mu \mathrm{g} / \mathrm{L})$} & \\
\hline 1 & $\overline{1,500}$ & 5.8 & $>3000$ & $<1$ & $<0.5$ & 0.5 & $<0.5$ & 2 & 20 \\
\hline 2 & 1,500 & 54 & $>3000$ & 10 & 18 & 0.4 & $<0.5$ & $<2$ & 320 \\
\hline 3 & 1,500 & 17 & $>3000$ & 6 & 0.7 & 0.4 & $<0.5$ & $<2$ & 100 \\
\hline 4 & 1,400 & 17 & $>3000$ & $<1$ & $<0.5$ & 0.5 & $<0.5$ & 5 & 10 \\
\hline 5 & 1,400 & 22 & $>3000$ & $<1$ & $<0.5$ & 0.3 & $<0.5$ & 4 & 20 \\
\hline 6 & 1,400 & 14 & $>3000$ & 1 & $<0.5$ & 0.3 & $<0.5$ & 3 & 20 \\
\hline 7 & 1,200 & 160 & $>3000$ & $<1$ & $<0.5$ & $<0.2$ & $<0.5$ & $<2$ & 30 \\
\hline 8 & 18 & 7 & 190 & $<1$ & 1 & $<0.2$ & $<0.5$ & $<2$ & 10 \\
\hline 9 & 34 & 3.2 & 230 & $<1$ & $<0.5$ & $<0.2$ & $<0.5$ & $<2$ & 9 \\
\hline 10 & 1,400 & 7 & $>3000$ & $<1$ & $<0.5$ & 0.2 & $<0.5$ & $<2$ & 20 \\
\hline 11 & 1,400 & 13 & $>3000$ & 1 & $<0.5$ & $<0.2$ & $<0.5$ & $<2$ & 10 \\
\hline 12 & 1,400 & 17 & $>3000$ & $<1$ & $<0.5$ & 0.2 & $<0.5$ & $<2$ & 20 \\
\hline
\end{tabular}

${ }^{1}$ Copper concentrations are likely to be $10 \mu \mathrm{g} / \mathrm{L}$ above true levels, due to chloride interference with the measurements, except for stations 8 and 9 , with 2 ppt salinity (see Table 2). 
Table 6. U.S.EPA acute (short-term exposure) and chronic (long-term exposure) water quality criteria for selected metals (in $\mu \mathrm{g} / \mathrm{L}$ ) in saltwater (USEPA, 1998), and station numbers at which criterion concentrations were exceeded in the filtered samples. Criteria are not available for other metals analyzed.

\begin{tabular}{|c|c|c|c|c|}
\hline Metal & $\begin{array}{l}\text { Acute } \\
\text { Criteria }\end{array}$ & $\begin{array}{l}\text { Chronic } \\
\text { Criteria }\end{array}$ & $\frac{\text { Acute criteria exceedances }}{\text { Stations }}$ & $\frac{\text { Chronic criteria exceedances }}{\text { Stations }}$ \\
\hline Cadmium & 42 & 9.3 & & \\
\hline Zinc & 90 & 81 & 2,3 & 2,3 \\
\hline Copper ${ }^{1}$ & 4.8 & 3.1 & $2,7,8$ & $2,7,8$ \\
\hline Lead & 210 & 8.1 & & 2 \\
\hline Silver & 1.9 & & $\mathrm{NA}^{2}$ & \\
\hline Nickel & 74 & 8.2 & & 2 \\
\hline
\end{tabular}

\section{Summary and Conclusions}

High toxicity was observed and elevated levels of metals were measured in the pore waters collected at the two stations nearest to the Calancan tailings causeway, although those sites were in the predominately upcurrent direction. Visual observations also indicated biological degradation, with heavy siltation and smothered coral at stations 2 through 5, suggesting that although samples from stations 4 and 5 were not toxic to sea urchin early life stages and did not present particularly elevated levels of metals, a physical impact might be caused by siltation.

The toxicity data and the visual observations suggest that the reestablishment of the benthic community, as well as of coral reefs and their associated fauna and flora, is unlikely to occur in the vicinity of the Calancan causeway. The elevated concentration of copper in the pore water from the station 2, closest to the causeway, suggests that this causeway is a constant source of copper contamination to the surrounding environment and is impairing the re-colonization of the area by the local natural biota.

This preliminary survey suggests that effects related to past mining activities are still evident and warrants a more comprehensive study to assess the severity and areal extent both up and down current of the tailings causeways.

\section{Acknowledgements}

We thank Congressman Edmund O. Reyes for the invitation to conduct this survey on Marinduque, and we are grateful for the warm welcome and continued logistical assistance given to us by the staff of Governor Carmencita Reyes during our stay in Marinduque. We are indebted to the expert technical assistance of Jim Biedenbach, Russell Hooten, and Linda May who processed the samples in the laboratory and conducted the toxicity tests, and to $\mathrm{Al}$ Meier and Peter Theodorakos for performing the chemical analyses. We thank Drs. Jack Medlin and Tom May for their helpful reviews of this report. 


\section{Literature Cited}

Carr, R.S. and J. M. Biedenbach. 1999. Use of power analysis to develop detectable significance criteria for sea urchin toxicity tests. Aquat. Ecosys. Health Manage. 2:413-418.

Carr, R.S. and D.C. Chapman. 1992. Comparison of solid-phase and pore-water approaches for assessing the quality of marine and estuarine sediments. Chem. Ecol. 7:19-30.

Carr, R.S., D.C. Chapman, C.L. Howard, J.M. Biedenbach. 1996a. Sediment quality triad assessment survey of the Galveston Bay, Texas system. Ecotoxicology 5:341-364.

Carr, R.S., E.R. Long, H.L. Windom, D.C. Chapman, G. Thursby, G.M. Sloane, D.A. Wolfe. 1996b. Sediment quality assessment studies of Tampa Bay, Florida. Environ. Toxicol. Chem. 15:1218-1231.

Carr, R.S., P.A. Montagna, J.M. Biedenbach, R. Kalke, M.C. Kennicutt, R. Hooten, G. Cripe. 2000. Impact of storm-water outfalls on sediment quality in Corpus Christi Bay, Texas, USA. Environ. Toxicol. Chem. 19:561-574.

Environment Canada. 1990. Guidance document on control of toxicity test precision using reference toxicants. Environmental Protection Series, Report EPS 1/RM/12. Environment Canada, Ottawa, Ontario, Canada.

Hamilton, M.A., R.C. Russo, R.V. Thurston. 1977. Trimmed Spearman-Karber method for estimating median lethal concentrations in toxicity bioassays. Environ. Sci. Technol. 11:714719; Correction 12:417 (1978).

Lamothe, P.J., A.L. Meier, S. Wilson. 1999. The Determination of Forty Four Elements in Aqueous Samples by Inductively Coupled Plasma - Mass Spectrometry. U.S. Geological Survey, Open-File Report 99-151, Denver, CO, 14 p.

Morgan, B.J.T. 1992. Analysis of Quantal Response Data, London, England: Chapman and Hall, $511 \mathrm{pp}$.

National Biological Service (NBS). 1995a. Toxicity testing of sediments from Biscayne Bay and Surrounding Areas. Report submitted by the National Biological Service to the National Oceanic and Atmospheric Administration, Coastal Monitoring and Bioeffects Division, Seattle, WA, 11 pp. + 17 tables, 11 figures and 4 attachments.

National Biological Service (NBS). 1995b. Toxicity testing of sediments from western Florida and coastal South Carolina and Georgia. Report submitted by the National Biological Service to the National Oceanic and Atmospheric Administration, Coastal Monitoring and Bioeffects Division, Seattle, WA, 14 pp. + 35 tables, 10 figures and 4 attachments.

National Biological Survey (NBS). 1993. Toxicity testing of sediments from Charleston Harbor, South Carolina and vicinity. Report submitted by the National Biological Survey to the National Oceanic and Atmospheric Administration, Ocean Assessment Division, Seattle, WA, 7 pp. +16 tables and 4 attachments.

National Biological Survey (NBS). 1994. Survey of sediment toxicity in Pensacola Bay and St. Andrew Bay, Florida. Report submitted by the National Biological Survey to the National Oceanic and Atmospheric Administration, Ocean Assessment Division, Seattle, WA, 12 pp. +24 tables and 5 attachments.

Nipper, M. and R.S. Carr. 2001. Porewater toxicity testing: a novel approach for assessing contaminant impacts in the vicinity of coral reefs. Bull Mar Sci 68 (in press). 
Plumlee, G.S., R.A. Morton, T.P. Boyle, J.H. Medlin, J. Ceteno. 2000. An Overview of Miningrelated Environmental Issues, Marinduque Island, Philippines: Observations from a Joint U.S. Geological Survey - Armed Forces Institute of Pathology Reconnaissance Field Evaluation, May 12-19, 2000. Denver, Colorado: U.S. Geological Survey, Open-File Report 00-397. 36 p. http://geology.cr.usgs.gov/pub/open-file-reports/ofr-00-0397/

SAS Institute Inc. 1992. SAS/LAB ${ }^{\circledR}$ Software: User's Guide, Version 6, First Edition, Cary, NC: SAS Institute Inc., $291 \mathrm{pp}$.

U.S. Environmental Protection Agency (USEPA). 1998. National recommended water quality criteria; republication. Federal Register, Part IV, v. 63, p. 68354-68364.

U.S. Fish and Wildlife Service (USFSW). 1992. Amphipod solid-phase and sea urchin porewater toxicity tests of Tampa Bay, Florida sediments. Report submitted by the U.S. Fish and Wildlife Service to National Oceanic and Atmospheric Administration, Ocean Assessment Division, Seattle, WA, 9 pp. +19 appendices.

U. S. Geological Survey (USGS). 1997. Toxicity testing of sediments from Biscayne Bay, Florida and surrounding areas - Phase II. Report submitted by the USGS to National Oceanic and Atmospheric Administration, Coastal Monitoring and Biological Assessment Division, Seattle, WA, 10 pp. +8 tables, 10 figures and 4 attachments.

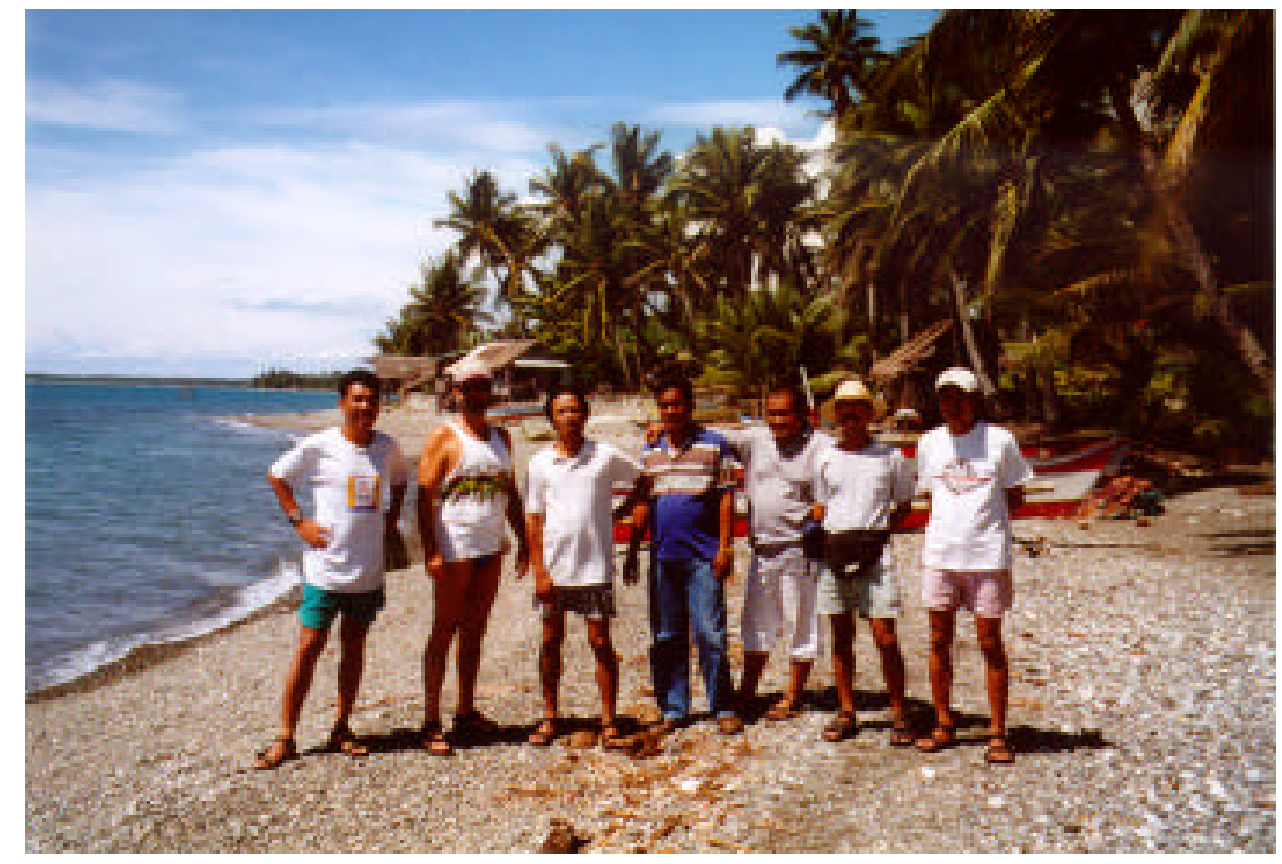

Sampling team left to right: Joven Lilles, Dr. Scott Carr, Dindo Asuncion, unidentified driver, driver Dan, Ton Monteagudo, Erwin Penafiel, and Dr. Marion Nipper (the photographer). 


\section{APPENDIX 1}

SOP F10.12

WATER QUALITY ADJUSTMENT OF SAMPLES 
Date Prepared: March 14, 1991

Date Revised: $\quad$ May 17, 1994

\section{WATER QUALITY ADJUSTMENT OF SAMPLES}

\subsection{OBJECTIVE}

In order to perform toxicity tests with saline samples, all test and reference samples should be similar in salinity so that salinity is not a factor in survival of test organisms. Additionally, dissolved oxygen (DO) concentrations should be sufficiently high to ensure that low DO is not a source of stress to the test organisms. At the Corpus Christi field station, toxicity tests are performed using a variety of marine and estuarine organisms, including the sea urchin Arbacia punctulata, the polychaete Dinophilus gyrociliatus, the harpacticoid copepod Longipedia sp., and the red drum Sciaenops ocellatus. The aqueous samples tested may be pore water, different kinds of discharges and effluents, surface microlayer, or subsurface water samples that may range in salinity from $0-36 \%$. Although from test to test salinities used in the different toxicity tests may vary, the individual toxicity tests performed on a particular day are run at a single target salinity. Since initial salinities of the porewater or water samples to be tested commonly vary, they will require salinity adjustment to within $1 \%$ of the target salinity. Additionally, DO should normally be $80 \%$ saturation in all samples tested.

\subsection{PREPARATION}

\subsection{Equipment and Labware}

The supplies and equipment needed are listed in Attachment 1.

\subsection{Source of Dilution Water}

For samples lower in salinity than target salinity, concentrated brine $\left(\_100 \%\right.$ oo $)$ is added to increase salinity. Concentrated brine is prepared by heating (to $35-40^{\circ} \mathrm{C}$ ) and gently aerating filtered natural seawater $(1 \mu \mathrm{m})$ to concentrate the salts by evaporation. For samples higher in salinity than target salinity, HPLC ultrapure sterile water (J.T. Baker® Cat. \#JT4218-2) is added to decrease salinity.

\subsection{PROCEDURES}

The following describes the procedures required for the adjustment and determination of specific water quality parameters of a sample. 


\subsection{Preparation for Salinity Adjustment}

1. Although fresh samples are routinely tested at the Corpus Christi field station, most of the samples tested are stored frozen in amber I-Chem ${ }^{\circledR}$ jars. If frozen, remove samples from freezer and allow them to thaw at room temperature or immerse them in a tepid water bath to thaw, ensuring that sample temperature does not exceed $25^{\circ} \mathrm{C}$. The samples may be thawed the day of water quality adjustment (WQA) or may be transferred from the freezer to a refrigerator $\left(4^{\circ} \mathrm{C}\right)$ the day before WQA and then completely thawed the following day. After thawing, allow the samples to come to room temperature. Generally, the samples should be maintained at the same temperature required for the toxicity test that will be conducted. The temperature requirement for most toxicity tests performed at this field station is $20 \pm 1^{\circ} \mathrm{C}$, and room temperature should be maintained accordingly.

2. Turn bottled sample end over end a few times to mix thoroughly before measuring salinity. Using a salinity refractometer, measure salinity and record on Water Quality Adjustment Data Form (Attachment 2).

3. In order to make calculations for the salinity adjustment, the volume of the sample must be known. When porewater or other water samples are collected and transferred to amber jars for storage, they are commonly measured to an approximate volume $(110 \mathrm{~mL}$, for example) prior to freezing. On the day of WQA, this volume should be recorded on the WQA data form for the respective samples. If the volume is unknown at this point, it should be measured using a graduated cylinder of appropriate size, and recorded on the data sheet.

\subsection{Salinity Adjustment}

\subsection{Reducing the salinity of aqueous samples}

Refer to the formulas below to calculate the volume of HPLC water needed to reduce the initial sample salinity to the target salinity. Add the volume calculated, mix the bottle thoroughly, check the salinity with a refractometer, and record the volume of HPLC water added as well as the final salinity.

(i) (target $\% \div$ sample $\%$ oo _ sample vol. in $\mathrm{mL}=\mathrm{A}$

(ii) sample vol $\div \mathrm{A}=\mathrm{B}$

(iii) sample vol. $\div \mathrm{A}=\mathrm{C}$

(iv) $\quad \mathrm{B}_{-} \mathrm{C}=$ volume of HPLC water to add

\subsection{Increasing the salinity of aqueous samples}

Refer to the formula below to calculate the volume of concentrated brine needed to increase the initial sample salinity to the target salinity. Add the volume calculated, mix the bottle thoroughly, check the salinity with a refractometer, and record the volume of brine added as well as the final salinity. 
(i) $\left(\left(\operatorname{target} \% \text { o } \%_{\text {omple }} \%_{\mathrm{oo}}\right)_{\text {_ }}\right.$ sample vol. in $\left.\mathrm{mL}\right) \div($ brine $\%$ o $\operatorname{target} \%)=$ vol. of brine to add

\subsection{Dissolved Oxygen Adjustment}

Measure and record DO and percent DO saturation of sample (SOP F10.13). Occasionally, a sample will have DO of less than $80 \%$ saturation. Any such samples should be gently stirred on a magnetic stirrer to increase the DO level above $80 \%$. Record initial DO, the elapsed mixing time, and final DO in the comments section of the Water Quality Adjustment Data Form. (On the following day, DO should be rechecked and brought to $>80 \%$ by stirring again if necessary before the toxicity test is performed.)

\subsection{Other Water Quality Determinations}

1. Measure $\mathrm{pH}$ (SOP F10.21) and record on the Water Quality Adjustment Data Form.

2. Measure and record ammonia concentration (SOP F10.4).

3. Measure and record sulfide concentration if required.

\subsection{DATA COLLECTION}

All raw data are entered on one standardized form, the Water Quality Adjustment Data Form (see Attachment 2) at the time the determinations or adjustments are made.

\subsection{QUALITY CONTROL}

A data form (Attachment 2) will be used to document all sample handling procedures for each sample. The person(s) recording data on the sheet will initial each sheet. Original data forms after completion will be stored in a three-ring file in the possession of the field station leader. Copies will be kept in the lab.

\subsection{TRAINING}

Personnel who will perform this task should first read this protocol and then operate under supervision during the preparation of at least two samples. 


\subsection{SAFETY}

The $\mathrm{NaOH}$ solution used in the ammonia determination procedure is a highly caustic liquid. Care should be taken to avoid its contact with skin or clothing. Should such contact occur, quickly flush affected with water. A sink is present along the west wall of the dry lab, another is present along the east wall of the wet lab, and an eye flushing station is present in the northwest corner of the wet lab near the entrance door. The samples handled may be pore water, effluent, discharges, or other water samples that may contain contaminants. Care should be taken to avoid contact with the samples.

\subsection{ATTACHMENTS}

Attachment 1. Equipment List for Water Quality Adjustment

Attachment 2. Water Quality Adjustment Data Form

Prepared by:

Duane C. Chapman

Fishery Biologist

Approved by:

R. Scott Carr

Field Station Leader

Anne E. Kinsinger

Chief, Field Research Division

Joseph B. Hunn

Quality Assurance Officer 


\section{ATTACHMENT 1}

\section{EQUIPMENT LIST FOR WATER QUALITY ADJUSTMENT}

Graduated cylinders

Pipetters

Latex gloves

Magnetic stirrer and stir bars

$10 \mathrm{M} \mathrm{NaOH}$

Concentrated brine (See section 2.2 for preparation)

HPLC ultrapure sterile water (J.T. Baker® \#JT4218-2)

Salinity refractometer

Dissolved oxygen meter

$\mathrm{pH}$ electrode, buffer solutions, and meter

Ammonia electrode, standard solutions, and meter

Sulfide electrode, standard solutions, and meter

Data sheets

Hand calculator 
ATTACHMENT 2

\title{
WATER QUALITY ADJUSTMENT DATA FORM
}

STUDY PROTOCOL SAMPLE DESIGNATION

A. Salinity Adjustment:
INITIALS

DATE

\author{
Initial volume $(\mathrm{mL})$ \\ Initial salinity $(\%)$ \\ Vol. Baker® HPLC water added (mL)
}

Vol. ___ $\%$ brine added $(\mathrm{mL})$

$\%$ of original sample

(initial vol./final vol. x 100)

B. Character of Sample (after salinity adjustment):

Final Volume (mL)

Final Salinity $(\%)$

$\mathrm{pH}$

Dissolved oxygen (mg/L)

DO saturation (\%)

Total ammonia (mg/L)

Sulfide (mg/L)

COMMENTS 
APPENDIX 2

SOP F10.6

SEA URCHIN FERTILIZATION TOXICITY TEST 
Date Prepared : April 10, 1990

Date Revised: March 10, 1995

\section{SEA URCHIN FERTILIZATION TOXICITY TEST}

\subsection{OBJECTIVE}

The purpose of the fertilization toxicity test with the sea urchin, Arbacia punctulata, is to determine if a sea water, pore water, sea surface microlayer, or other sample reduces fertilization of exposed gametes relative to that of gametes exposed to a reference sample. The test may also be used to determine the concentration of a test substance which reduces fertilization. Test results are reported as treatment (or concentration) which produces statistically significant reduced fertilization or as concentration of test substance which reduces fertilization by 50 percent $\left(\mathrm{EC}_{50}\right)$. This test can be performed concurrently with Sea Urchin Embryological Development Toxicity Test (SOP 10.7) and/or Sea Urchin Genotoxicity/Teratogenicity Test (SOP 10.8), using the same pretest and sperm and egg collection.

\subsection{TEST PREPARATION}

\subsection{Test Animals}

Gametes from the sea urchin, Arbacia punctulata are used in the sea urchin fertilization toxicity test. Animals can be collected in the field or obtained from a commercial supplier. A. punctulata can be differentiated from other species of urchins which are found in Texas by the five plates surrounding the anal opening, and by round sharp spines on the dorsal surface of the test and flattened spines surrounding the Aristotle's lantern. Urchins can be maintained easily in aquaria or other tanks with running seawater or an aquarium filter. Urchins will eat a wide variety of marine vegetation. A good diet may be provided by placing rocks from jetties (which have been colonized by diatoms and macroalgae) into the tank with the urchins or romaine lettuce may be provided as a substitute. Temperature manipulations of the cultures will prolong the useful life of the urchins. Cultures are maintained at $16 \pm 1 \subseteq \mathrm{C}$ when gametes are not required. Temperature is gradually increased to $19 \pm 1 \boxminus \mathrm{C}$ at least one week prior to gamete collection and subsequently decreased if no further tests are planned. Photoperiod is maintained at 16 hours of light per day. Water quality parameters should be monitored weekly and salinity maintained at $30 \pm 3 \%$. Males and females should be kept in separate tanks. 


\subsection{Dilution Water}

HPLC reagent grade purified water or concentrated seawater brine is used to adjust samples to $30 \%$ as described in Water Quality Adjustment of Samples (SOP 10.12). Concentrated seawater brine $(90-110 \%$ o $)$ is made in large batches by heating seawater to $40^{\circ} \mathrm{C}$ or less in large tanks with aeration for 3-4 weeks. Brine quality will remain constant over long periods with no refrigeration. At the time of salinity adjustment, $\mathrm{pH}$, ammonia, and dissolved oxygen are also measured. Salinity adjustment and water quality data are recorded on prepared data forms.

Filtered $(0.45 \mu \mathrm{m})$ seawater adjusted to $30 \%$ is used to wash eggs and is also used for sperm and egg dilutions. The acronym MFS (for Millipore ${ }^{\circledR}$ filtered seawater) is used for this filtered and salinity adjusted seawater.

\subsection{Test System: Equipment}

When testing samples for potential toxicity, five replicates per treatment are recommended. One replicate is a $5 \mathrm{~mL}$ volume of sample in a disposable glass scintillation vial. When conducting a dilution series test, fifty percent serial dilutions may be made in the test vials, using MFS as the diluent.

\subsubsection{Equipment}

A list of equipment necessary for conducting this test is given in Attachment 1 (Equipment List for Fertilization Toxicity Test).

\subsubsection{Solutions}

$\underline{10 \% \text { Buffered Formalin: }}$

$1,620 \mathrm{~mL}$ sea water

$620 \mathrm{~mL}$ formaldehyde

$6.48 \mathrm{~g} \mathrm{NaH}_{2} \mathrm{PO}_{4}$ or $\mathrm{KH}_{2} \mathrm{PO}_{4}$ (mono)

$10.5 \mathrm{~g} \mathrm{Na}_{2} \mathrm{HPO}_{4}$ or $\mathrm{K}_{2} \mathrm{HPO}_{4}$ (dibasic)

$1 \mathrm{~mL}$ needed for each replicate. Fill the dispenser.

\subsection{Collection and Preparation of Gametes}

Quality gametes must first be collected, and then diluted to the appropriate concentration for addition to the test vial. 


\subsubsection{Selection of Urchins to be Used in Toxicity Test.}

1. Take two or three females and place in shallow bowl, barely covering tests with seawater.

2. Stimulate release of eggs from gonopores of a female by touching test with electrodes from a $12 \mathrm{~V}$ transformer.

3. Collect a few eggs from between spines using a $10 \mathrm{~mL}$ disposable syringe with a large gauge blunt-tipped needle attached. Discard the first small quantity of eggs expelled from each gonopore and continue collecting. Place a 2 to 5 drops of eggs onto a scintillation vial containing $10 \mathrm{ml}$ of filtered seawater. Rinse syringe and repeat for each female.

4. Select females which have round, well developed eggs, and which do not release clumps of eggs or undeveloped ovarian tissue.

5. Place 2-4 males in shallow bowl(s) with a small amount of seawater, leaving the upper $1 / 2$ to $1 / 3$ of the animals uncovered.

6. Stimulate release of sperm from gonopores by touching test with electrodes from $12 \mathrm{~V}$ transformer (about 30 seconds each time). If sperm is watery, reject the animal and choose another. Sperm should be the consistency of condensed milk. Collect sperm using a pasteure pipette with a rubber bulb attached.

Generally, a gamete check is performed in order to ensure that both the male and the female urchins used in the test have gametes with a high degree of viability. If the gamete check is performed, two to five females (depending on confidence in the proportion of urchins in the holding facility in good reproductive status) and at least two males should be selected using the above procedures. The check is performed by adding 5 to 7 drops of a concentrated dilution of sperm to the eggs in the scintillation vials (collected as described above) and observing the eggs under the microscope after 10 minutes. The concentrated dilution of sperm is usually made by diluting $20-50 \mu \mathrm{l}$ of sperm in $10 \mathrm{ml}$ of filtered seawater. If the proportion of eggs fertilized is high $(95-100 \%)$, that female and male may be used in the pretest and test. Sperm from a number of males or females may be combined in the beginning if the gamete check reveals a number of high quality animals or the confidence is high in the quality of the gametes. Once a good male and female are selected a pretest can be conducted to determine the correct dilution of sperm to use in the test (Attachment 2).

\subsubsection{Obtain Eggs}

1. Place selected female in large Carolina dish and add enough water to cover the urchin's test with approximately $1 \mathrm{~cm}$ of seawater. Stimulate release of eggs from female with $12 \mathrm{~V}$ transformer. 
2. Collect eggs as above using the $10 \mathrm{~mL}$ syringe. Remove needle before dispensing eggs into a disposable shell vial or other clean container capable of holding 25-50 mL. Collect enough eggs for pretest and test. If female stops giving eggs readily or starts giving chunky material, cease stimulation and collection of eggs from that female.

3. Add MFS to fill shell vials, gently mixing eggs. Allow eggs to settle to bottom of vial. Remove water with a pipette. Replace water, again gently mixing the eggs.

4. Repeat washing procedure.

\subsubsection{Prepare Appropriate Egg Concentration}

1. Put approximately $100 \mathrm{~mL}$ of $30 \%$ MFS in a $250 \mathrm{~mL}$ beaker, and add enough washed eggs to bring the egg density to approximately 10,000 per $\mathrm{mL}$. If more than 400 total replicates (27 treatments) are to be tested, a larger amount of water and a correspondingly larger amount of eggs should be used. Two hundred $\mu \mathrm{L}$ of this egg solution will be used per replicate, and it is easier to maintain proper mixing and uniform egg density if there is an excess of at least $50 \%$.

2. Check egg density and adjust to within approximately 9000 to 11,000 eggs per $\mathrm{mL}$, as follows. Gently swirl egg solution until evenly mixed. Using a pipette, add $1 \mathrm{~mL}$ of the solution to a vial containing nine $\mathrm{mL}$ seawater. Mix and transfer $1 \mathrm{~mL}$ of this diluted solution to a second vial containing $4 \mathrm{~mL}$ of seawater. Again, mix and transfer $1 \mathrm{~mL}$ of this diluted solution to a counting slide such as a Sedgewick-Rafter slide.

3. Using a microscope (either a compound microscope with a 10x objective or a dissecting scope may be used here), count the number of eggs on the slide. If the number is not between 180 and 220, then adjust by adding eggs or water. If egg count is $>220$ use the following formula to calculate the amount of water to add:

("egg count" - 200/200) x Current Volume of Eggs = Volume seawater to add to stock (mLs)

If egg count $<200$ add a small amount of eggs. Since it is less arbitrary and more likely to arrive at an acceptable count when using the water addition formula, it is better to originally overestimate the amount of eggs to add to the $100 \mathrm{~mL}$ of water.

4. Repeat steps 2 and 3 until an acceptable egg count (between 180 and 220) is obtained.

\subsubsection{Obtain Sperm}

Place selected male urchin in a large Carolina dish containing 1-2 $\mathrm{cm}$ of water. About half of test should be above water level. Stimulate male with $12 \mathrm{~V}$ transformer, and collect about $0.5 \mathrm{~mL}$ of unwetted sperm from between spines using a pasteur pipette. Place sperm into a plastic microcentrifuge tube. Keep on ice until used. Be careful not to 
add any water or sperm which has contacted water to the vials. High quality sperm collected dry and kept on ice will last at least eight hours without measurable decline in viability.

\subsubsection{Prepare Appropriate Sperm Dilution}

It is desirable for control fertilization to be within 60-90\%. Although controls outside these bounds do not automatically disqualify a test, particularly if a valuable dose response is generated, the sensitivity of the test is reduced by fertilization rates greater than $90 \%$ and good dose responses may be difficult to obtain with less than $60 \%$ fertilization in controls. Density of sperm in the sperm solution should be determined with this goal in mind. Condition of the animals and length of acclimation to the aquarium may affect the chosen sperm density. The pretest (Attachment 2) may be used to calculate an appropriate sperm dilution. Generally, a dilution of between 1:10,000 and 1:2500 will result in desirable fertilization rates, if the animals are in good condition.

For example, if a sperm dilution of 1:5000 is required (as determined from the pretest), add $20 \mu \mathrm{L}$ sperm to $10 \mathrm{~mL}$ MFS. Mix thoroughly, then add $1 \mathrm{~mL}$ of this solution to $9 \mathrm{~mL}$ MFS. Sperm should not be wetted until just before starting the test. Sperm wetted more than 30 minutes before the test has begun, including sperm dilutions used in any pretest, should be discarded and a new dilution made from sperm kept on ice.

\subsection{TEST PROCEDURES}

1. Add $50 \mu \mathrm{L}$ appropriately diluted sperm to each vial. Record time of sperm addition. Sperm should be used within 30 minutes of wetting.

2. Incubate all test vials at $20 \pm 2{ }^{\circ} \mathrm{C}$ for 30 minutes. At this point it is useful to set a timer for five to ten minutes prior to the end of the incubation period. This will notify the worker early enough to be ready to start the next step exactly on time.

3. While gently swirling the egg solution to maintain even mixing of eggs, use a $200 \mu \mathrm{L}$ pipetter to add $200 \mu \mathrm{L}$ diluted egg suspension to each vial. Pipette tips are cut back using a clean razor blade to prevent crushing the eggs during pipetting. Record time of egg addition.

4. Incubate for 30 minutes at $20 \pm 2^{\circ} \mathrm{C}$. The timer may be used again at this point.

5. Using the dispenser, add $1 \mathrm{~mL}$ of $10 \%$ buffered formalin to each sample.

6. Vials may now be capped and stored overnight or for several days until evaluated. Fertilization membranes are easiest to see while eggs are fairly fresh, so evaluation within two to three days may decrease the time required for evaluation. 
7. If it is not possible to make the evaluations within several days or the membranes are difficult to discern, an optional technique may be employed. Make up a $200 \% \mathrm{NaCl}$ solution (pickling salt) and add 2 to 4 drops of the solution to a $1 \mathrm{~mL}$ egg sample on a microscope slide. This solution causes the egg, but not the membrane, to shrink briefly thereby making the membrane easier to see. The effect only lasts for a short time $(\sim 5$ min.) so the observations must be made immediately after the $\mathrm{NaCl}$ solution is added. If this optional technique is employed, it must be used on all samples in that test series.

\subsection{DATA COLLECTION AND TABULATION}

1. Transfer approximately $1 \mathrm{~mL}$ eggs and water from bottom of test vials to counting slide. Observe eggs using compound microscope under 100X magnification. Dark field viewing is useful here in identifying fertilization membranes.

2. Count 100 eggs/sample using hand counter with multiple keys (such as a blood cell counter), using one key to indicate fertilized eggs and another to indicate unfertilized eggs. Fertilization is defined by the presence of fertilization membrane surrounding egg.

3. Calculate fertilization percentage for each replicate test:

Total No. Eggs - No. Eggs Unfertilized x $100=$ Percent Eggs Fertilized Total No. Eggs

\subsection{DATA ANALYSIS}

Data are recorded on standardized data sheets (See Attachments 3-7). Normally, percent fertilization in each treatment is compared to an appropriate reference treatment (seawater, pore water or sea surface microlayer from an uncontaminated environment). Statistical comparisons are made using analysis of variance (ANOVA) and Dunnett's $t$-test (Sokal and Rohlf 1981) on the arc sine square root transformed data. For multiple comparisons among treatments, Ryan's Q test (Day and Quinn 1989) with the arc sine square root transformed data is recommended. The trimmed Spearman-Karber method with Abbott's correction is recommended to calculate $\mathrm{EC}_{50}$ values for dilution series tests (Hamilton et al. 1977)

\subsection{QUALITY CONTROL}

Quality control tests may be run using both positive and negative controls with multiple replicates (as many as desired). Typically, a reference toxicant dilution series (sodium dodecyl sulfate) is tested with each test to evaluate the effectiveness of the sperm dilution chosen. Negative controls may include a reference porewater, filtered seawater, and/or a reconstituted brine. 


\subsection{TRAINING}

A trainee will conduct the test with supervision initially. Determining egg concentrations and fertilization counts are test specific activities. These functions can be performed independently after a trainee has demonstrated he or she can accurately reproduce the test.

\subsection{SAFETY}

The sea urchin fertilization toxicity test poses little risk to those performing it. Care should be taken when making and dispensing the $10 \%$ buffered formalin solution; use a hood if available, but make sure the test area is well ventilated. Protective gloves can be worn when pipetting or dispensing formalin or potentially toxic samples.

Care should be taken when collecting or otherwise handling sea urchins. Urchin spines are sharp and fragile and may puncture the skin and break off if handled roughly. First aid similar to treatment of wood splinters is effective in this case (removal of spine and treatment with antiseptic). Collection of sea urchins by snorkeling should not be done alone.

\subsection{ATTACHMENTS}

Attachment 1. Equipment List for Fertilization Toxicity Test

Attachment 2. Pretest to Insure Selection of Quality Gametes

Attachment 3. Water Quality Adjustment Data Form

Attachment 4. Sea Urchin Pretest Data Sheet

Attachment 5. Sea Urchin Pretest Continuation Data Sheet

Attachment 6. Sea Urchin Fertilization/Embryological Development Toxicity Test Gamete

Data Sheet

Attachment 7. Sea Urchin Fertilization Toxicity Test Fertilization Data Sheet

\subsection{REFERENCES}

Day, R.W. and G.P. Quinn. 1989. Comparisons of treatments after an analysis of variance in ecology. Ecol. Monogr. 59:433-463.

Hamilton, M.A., R.C. Russo, and R.V. Thurston. 1977. Trimmed Spearman-Karber method for estimating median lethal concentrations in toxicity bioassays. Environ. Sci. Technol. 11(7):714-719; Correction 12(4):417 (1978)

Sokal, R.R., and F.J. Rohlf. 1981. Biometry. $2^{\text {nd }}$ edition. W.H. Freeman and Company, San Francisco, CA 859 pp. 
Prepared by:

Duane Chapman

Fishery Biologist

Approved by:

R. Scott Carr

Field Station Leader

Anne E. Kinsinger

Chief, Field Research Division

Joseph B. Hunn

Quality Assurance Officer 


\section{Attachment 1 \\ EQUIPMENT LIST FOR FERTILIZATION TOXICITY TEST}

Large Carolina dishes (at least 2)

20 mL KIMBLE scintillation vials (These should be type shipped with caps off, and without cap

liners. If other brand or type is used, the vials should be tested for toxicity prior to use.)

$400 \mathrm{~mL}$ beaker or wide-mouthed thermos for holding vials of sperm

$250 \mathrm{~mL}$ beakers (4)

Pasteur pipettes and latex bulbs

plastic microcentrifuge tubes

$25 \mathrm{~mL}$ shell vials or equivalent

Test tube rack (to hold shell vials)

$12 \mathrm{~V}$ transformer with pencil type electrodes

Styrofoam (or something to hold electrode tips)

$10 \mathrm{cc}$ syringe with large diameter blunt ended needle (make by grinding sharp point off the needle with a grinding stone)

Marking pens

Ice

$10-100 \mu \mathrm{L}$ pipetter

$50-200 \mu \mathrm{L}$ pipetter

$5 \mathrm{~mL}$ pipetters (2)

Counting slide such as Sedgewick-Rafter chamber

Compound microscope with 10x objective and dark field capability

Hand tally counter

Calculator

Timer for exposure / incubation periods

Buffered formalin and dispenser

Filtered $(0.45 \mu \mathrm{m})$ seawater, adjusted to $30 \%$

Data sheets

Baker reagent grade water

Approximately $100 \%$ concentrated brine 


\section{Attachment 2 PRETEST TO INSURE SELECTION OF QUALITY GAMETES}

1. Using the procedure in section 2.4.1, select 2 to 5 females and at least 2 male urchins to be used in the pretest.

2. Fill pretest vials with five $\mathrm{mL}$ of reference water. There should be at least two vials for each combination of male, female, and pretest sperm concentration (step 4 below). For example, in a pretest with two females, one male, and six pretest sperm concentrations, 24 vials ( 2 X 2 X 6) would be needed. Arrange and mark vials accordingly in a rack.

3. Perform steps 2.4.2 (egg collection) and 2.4.3 (egg dilution) for each female urchin. Make enough volume of the egg suspension to perform the pretest and the test.

4. Perform step 2.4.4 (sperm collection) for each male urchin or male combination. Prepare a dilution series of sperm concentrations which will bracket the $60-90 \%$ fertilization rate in the test. Sperm dilution will depend on the health and reproductive status of the male urchin, but in most cases the following "standard dilution" should be used:

1: $250(20 \mu \mathrm{L}$ dry sperm added to $5 \mathrm{~mL}$ MFS. This concentration is used only as stock solution to make up the rest of the dilution series and is not used full strength in the pretest.)

1: 1250 (1 mL of 1:250 and $4 \mathrm{~mL}$ MFS)

1: 2500 (1 $\mathrm{mL}$ of $1: 250$ and $9 \mathrm{~mL}$ MFS)

1: 5000 (2 mL of 1:2500 and $2 \mathrm{~mL} \mathrm{MFS})$

1: 7500 (2 mL of 1:2500 and $4 \mathrm{~mL}$ MFS)

$1: 10000$ ( $3 \mathrm{~mL}$ of $1: 7500$ and $1 \mathrm{~mL}$ MFS)

$1: 12500(1 \mathrm{~mL}$ of $1: 2500$ and $4 \mathrm{~mL}$ MFS)

Sperm must be used within 30 minutes of dilution. Leave undiluted sperm on ice and retain, because a new sperm dilution of the concentration determined in this pretest will be needed for the toxicity test. Sperm diluted for use in the pretest may not be used in the toxicity test, because the time elapsed since the addition of water is too great.

5. As in section 3.0 add $50 \mu \mathrm{L}$ of the diluted sperm to each pretest vial. Incubate for 30 minutes at approximately $20^{\circ} \mathrm{C}$, and add $200 \mu \mathrm{L}$ of the egg suspension. Incubate for another 30 minutes, then fix with $1 \mathrm{~mL}$ of the buffered formalin solution.

6. As in section 4.0, obtain a fertilization rate for the vials. There is no need to count all vials, enough vials should be counted to determine a good male/female combination, and an appropriate sperm dilution factor. If more than one male/female combination is acceptable, this is a good opportunity to choose a female which exhibits easily visible fertilization membranes or in cases where there are many samples, to combine eggs from different females . The appearance of the fertilization membranes may vary among female urchins, and presence of easily visible membranes facilitates counting. 
Attachment 3

\section{WATER QUALITY ADJUSTMENT DATA FORM}

STUDY PROTOCOL

SAMPLE DESIGNATION

A. Salinity Adjustment:

Initial volume $(\mathrm{mL})$

Initial salinity $(\%)$

Vol. Milli-Q water added (mL)

Vol. __ $\%$ brine added $(\mathrm{mL})$

$\%$ of original sample

(initial vol./final vol. x 100)

\section{INITIALS}

DATE

B. Character of Sample (after salinity adjustment):

Volume (mL)

Salinity $(\%)$

$\mathrm{pH}$

Dissolved oxygen (mg/L)

DO saturation (\%)

Total ammonia (mg/L)

Sulfide (mg/L)

COMMENTS 
Attachment 4

\section{SEA URCHIN PRETEST DATA SHEET}

TEST ID

STUDY PROTOCOL

\section{EGGS}

Female number:

Collection time:

Count:

\section{SPERM}

Male number:

Collection time:

Dilution start time:

\section{TEST TIMES}

Sperm in:

Eggs in:

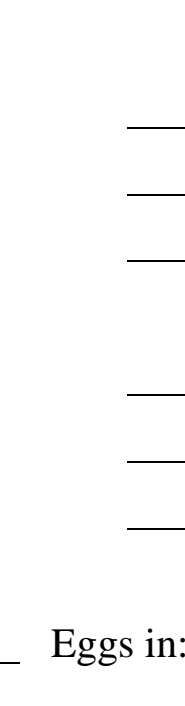

\section{SPERM DILUTION}

\section{COMMENTS}

\% FERTILIZATION Reference sample designation:

Female \#

\section{INITIALS}

DATE

DATE 
Attachment 5

SEA URCHIN PRETEST CONTINUATION DATA SHEET TEST ID INITIALS

STUDY PROTOCOL DATE

\% FERTILIZATION Reference sample designation:

Female \#

Male \#

\begin{tabular}{lllll} 
Sperm dilution & REP 1 & REP 2 & REP 3 & REP 4 \\
\hline+ & - & - & - & - \\
\hline+ & - & - & - & - \\
\hline \hline
\end{tabular}

\% FERTILIZATION Reference sample designation:

Female \#

Male \#

Sperm dilution

REP 1

REP 2

REP 3

REP 4

\% FERTILIZATION Reference sample designation:

Female \#

Male \#

\begin{tabular}{lllll} 
Sperm dilution & REP 1 & REP 2 & REP 3 & REP 4 \\
\hline \hline & - & - & - & - \\
\hline & - & - & - & - \\
\hline \hline
\end{tabular}

\% FERTILIZATION Reference sample designation:

Female \#

Male \#

Sperm dilution

REP 1

REP 2

REP 3

REP 4
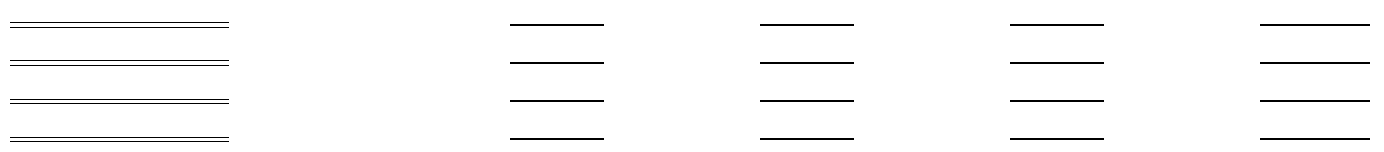
Attachment 6

\section{SEA URCHIN FERTILIZATION/EMBRYOLOGICAL DEVELOPMENT TOXICITY TEST GAMETE DATA SHEET}

TEST ID

STUDY PROTOCOL

Collection time:

Initial count/volume:

Final count:

\section{SPERM}

Collection time:

Dilution start time:

Sperm dilution:

Test start temperature:

\section{TEST TIMES}

Box \#

Sperm in:

Eggs in:

Formalin in:
INITIALS

DATE

\section{EGGS}


Attachment 7

\section{SEA URCHIN FERTILIZATION TOXICITY TEST}

\section{FERTILIZATION DATA SHEET}

TEST ID

STUDY PROTOCOL

Treatment

$\underline{1}$

$\underline{2}$

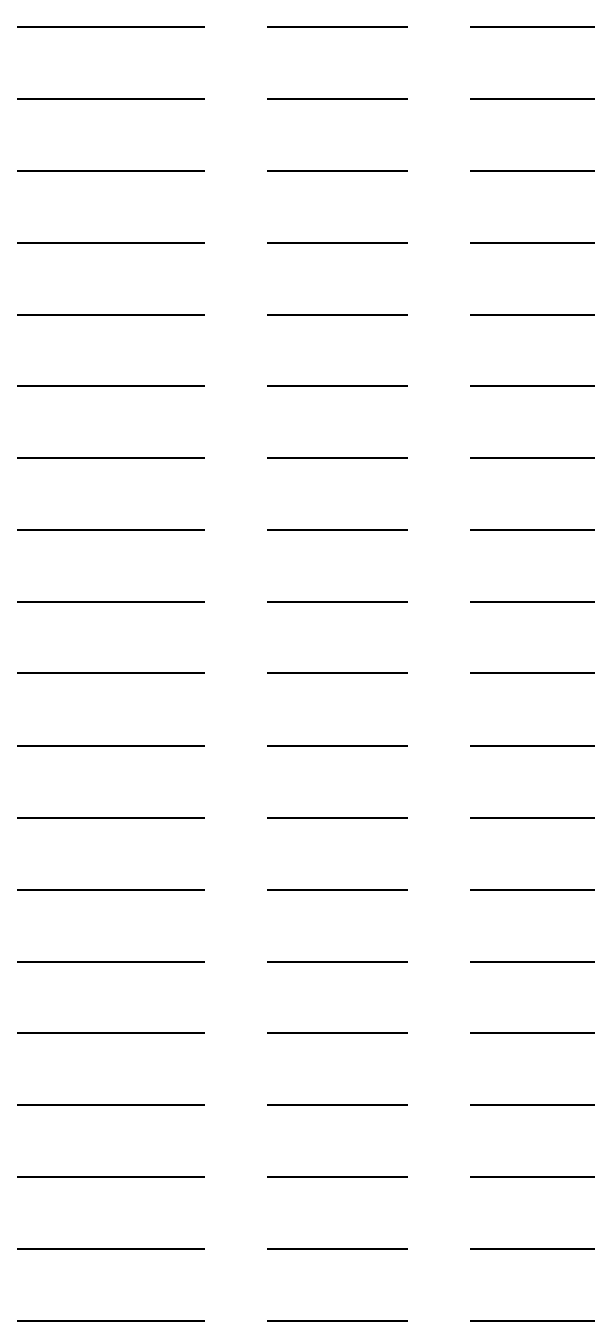

PERCENT FERTILIZED

Replicate

$\begin{array}{llll}\underline{3} & \underline{5} & \underline{M}\end{array}$
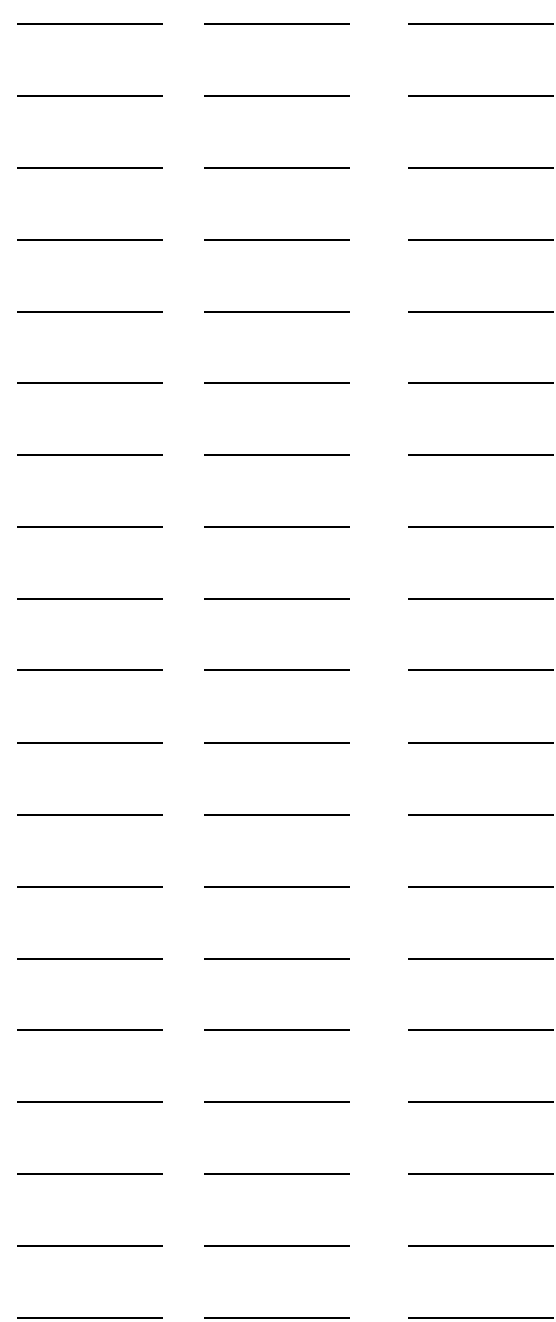

INITIALS

DATE

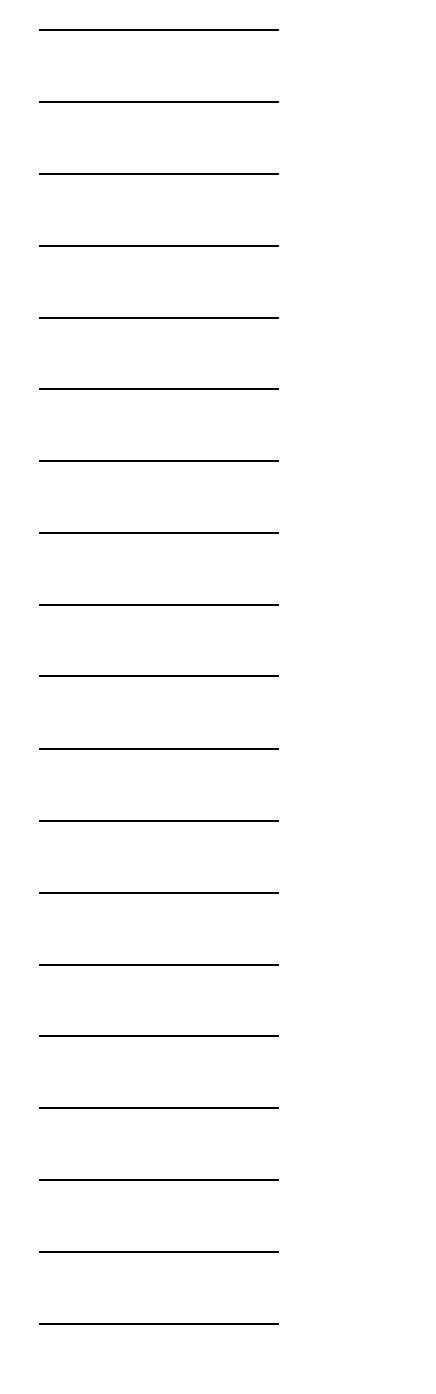




\section{APPENDIX 3}

\section{SOP F10.7}

SEA URCHIN EMBRYOLOGICAL DEVELOPMENT TOXICITY TEST 
Date Prepared : April 10, 1990

Date Revised: February 29, 2000

\section{SEA URCHIN EMBRYOLOGICAL DEVELOPMENT TOXICITY TEST}

\subsection{OBJECTIVE}

The purpose of the embryological development toxicity test with the sea urchin, Arbacia punctulata, is to determine if a sea water, pore water, sea surface microlayer, or other sample affects development of exposed embryos (development arrested at an early stage or a developmental abnormality) relative to that of embryos exposed to a reference sample. The test may also be used to determine the concentration of a test substance which affects development. Test results are reported as treatment (or concentration) which produces statistically significant developmental effect. This test can be performed concurrently with Sea Urchin Fertilization Toxicity Test (SOP 10.6) and/or Sea Urchin Genotoxicity/Teratogenicity Test (SOP 10.8), using the same pretest and sperm and egg collection.

\subsection{TEST PREPARATION}

\subsection{Test Animals}

Gametes from the sea urchin, Arbacia punctulata are used in the sea urchin embryological development toxicity test. Animals can be collected in the field or obtained from a commercial supplier. A. punctulata can be differentiated from other species of urchins which are found in Texas by the five plates surrounding the anal opening, and by round sharp spines on the dorsal surface of the test and flattened spines surrounding the Aristotle's lantern. Urchins can be maintained easily in aquaria or other tanks with running seawater or an aquarium filter. Urchins will eat a wide variety of marine vegetation. A good diet may be provided by placing rocks from jetties (which have been colonized by diatoms and macroalgae) into the tank with the urchins or romaine lettuce may be provided as a substitute. Temperature manipulations of the cultures will prolong the useful life of the urchins. Cultures are maintained at $16 \pm 1 \rrbracket \mathrm{C}$ when gametes are not required. Temperature is gradually increased to $19 \pm 1 \rrbracket \mathrm{C}$ at least one week prior to gamete collection and subsequently decreased if no further tests are planned. Photoperiod is maintained at 16 hours of light per day. Water quality parameters should be monitored weekly and salinity maintained at $30 \pm 3 \%$. Males and females should be kept in separate tanks. 


\subsection{Dilution Water}

HPLC reagent grade purified water or concentrated seawater brine is used to adjust samples to $30 \%$ as described in Water Quality Adjustment of Samples (SOP 10.12). Concentrated seawater brine $(90-110 \%$ o $)$ is made in large batches by heating seawater to $40 \curvearrowleft \mathrm{C}$ or less in large tanks with aeration for 3-4 weeks. Brine quality will remain constant over long periods with no refrigeration. At the time of salinity adjustment, $\mathrm{pH}$, ammonia, and dissolved oxygen are also measured. Salinity adjustment and water quality data are recorded on prepared data forms.

Filtered $(0.45 \mu \mathrm{m})$ seawater adjusted to $30 \%$ is used to wash eggs and is also used for sperm and egg dilutions. The acronym MFS (for Millipore ${ }^{\circledR}$ filtered seawater) is used for this filtered and salinity adjusted seawater.

\subsection{Test System: Equipment}

When testing samples for potential toxicity, five replicates per treatment are recommended. One replicate is a $5 \mathrm{~mL}$ volume of sample in a disposable glass scintillation vial. When conducting a dilution series test, fifty percent serial dilutions may be made in the test vials, using MFS as the diluent.

\subsubsection{Equipment}

A list of equipment necessary for conducting this test is given in Attachment 1 (Equipment List for Embryological Development Toxicity Test).

\subsubsection{Solutions}

10\% Buffered Formalin:

$1,620 \mathrm{~mL}$ sea water $620 \mathrm{~mL}$ formaldehyde

$6.48 \mathrm{~g} \mathrm{NaH}_{2} \mathrm{PO}_{4}$ or $\mathrm{KH}_{2} \mathrm{PO}_{4}$ (mono)

$10.5 \mathrm{~g} \mathrm{Na}_{2} \mathrm{HPO}_{4}$ or $\mathrm{K}_{2} \mathrm{HPO}_{4}$ (dibasic)

$0.75 \mathrm{~mL}$ needed for each replicate. Fill the dispenser.

\subsection{Collection and Preparation of Gametes}

Quality gametes must first be collected, and then diluted to the appropriate concentration for addition to the test vials. 


\subsubsection{Selection of Urchins to be Used in Toxicity Test.}

1. Take two or three females and place in shallow bowl, barely covering tests with seawater.

2. Stimulate release of eggs from gonopores of a female by touching test with electrodes from a $12 \mathrm{~V}$ transformer.

3. Collect a few eggs from between spines using a $10 \mathrm{~mL}$ disposable syringe with a large gauge blunt-tipped needle attached. Discard the first small quantity of eggs expelled from each gonopore and continue collecting. Place a 2 to 5 drops of eggs onto a scintillation vial containing $10 \mathrm{~mL}$ of filtered seawater. Rinse syringe and repeat for each female.

4. Select females which have round, well developed eggs, and which do not release clumps of eggs or undeveloped ovarian tissue.

5. Place 2-4 males in shallow bowl(s) with a small amount of seawater, leaving the upper $1 / 2$ to $1 / 3$ of the animals uncovered.

6. Stimulate release of sperm from gonopores by touching test with electrodes from $12 \mathrm{~V}$ transformer (about 30 seconds each time). If sperm is watery, reject the animal and choose another. Sperm should be the consistency of condensed milk. Collect sperm using a pastuere pipette with a rubber bulb attached.

Generally, a gamete check is performed in order to ensure that both the male and the female urchins used in the test have gametes with a high degree of viability. If the gamete check is performed, two to five females and at least two males should be selected using the above procedures. The check is performed by adding 5 to 7 drops of a concentrated dilution of sperm to the eggs in the scintillation vials (collected as described above) and observing the eggs under the microscope after 10 minutes. The concentrated dilution of sperm is usually made by diluting $20-50 \mu \mathrm{L}$ of sperm in $10 \mathrm{~mL}$ of filtered seawater. If the proportion of eggs fertilized is high (95-100\%), that female and male may be used in the pretest and test. Sperm from a number of males or eggs of females may be combined if the gamete check reveals a number of high quality animals or the confidence is high in the quality of the gametes. Once a good male and female are selected a pretest can be conducted to determine the correct dilution of sperm to use in the test (Attachment 2).

\subsubsection{Obtain Eggs}

1. Place selected female in large Carolina dish and add enough water to cover the urchin's test with approximately $1 \mathrm{~cm}$ of seawater. Stimulate release of eggs from female with $12 \mathrm{~V}$ transformer. 
2. Collect eggs as above using the $10 \mathrm{~mL}$ syringe. Remove needle before dispensing eggs into a disposable shell vial or other clean container capable of holding 25-50 mL. Collect enough eggs for pretest and test. If female stops giving eggs readily or starts giving chunky material, cease stimulation and collection of eggs from that female.

3. Add MFS to fill shell vials, gently mixing eggs. Allow eggs to settle to bottom of vial. Remove water with a pipette. Replace water, again gently mixing the eggs.

4. Repeat washing procedure.

\subsubsection{Prepare Appropriate Egg Concentration}

1. Put approximately $100 \mathrm{~mL}$ of $30 \%$ MFS in a $250 \mathrm{~mL}$ beaker, and add enough washed eggs to bring the egg density to approximately 10,000 per $\mathrm{mL}$. If more than 400 total replicates (27 treatments) are to be tested, a larger amount of water and a correspondingly larger amount of eggs should be used. Two hundred $\mu \mathrm{L}$ of this egg solution will be used per replicate, and it is easier to maintain proper mixing and uniform egg density if there is an excess of at least $50 \%$.

2. Check egg density and adjust to within approximately 9000 to 11,000 eggs per $\mathrm{mL}$, as follows. Gently swirl egg solution until evenly mixed. Using a pipette, add $1 \mathrm{~mL}$ of the solution to a vial containing nine $\mathrm{mL}$ seawater. Mix and transfer $1 \mathrm{~mL}$ of this diluted solution to a second vial containing $4 \mathrm{~mL}$ of seawater. Again, mix and transfer $1 \mathrm{~mL}$ of this diluted solution to a counting slide such as a Sedgewick-Rafter slide.

3. Using a microscope (either a compound microscope with a 10x objective or a dissecting scope may be used here), count the number of eggs on the slide. If the number is not between 180 and 220, then adjust by adding eggs or water. If egg count is > 220 use the following formula to calculate the amount of water to add:

("egg count" - 200/200) x Current Volume of Eggs = Volume seawater to add to stock $(\mathrm{mL})$

If egg count $<200$ add a small amount of eggs. Since it is less arbitrary and more likely to arrive at an acceptable count when using the water addition formula, it is better to originally overestimate the amount of eggs to add to the $100 \mathrm{~mL}$ of water.

4. Repeat steps 2 and 3 until an acceptable egg count (between 180 and 220) is obtained.

5. Just before the eggs are to be used, add $2 \mathrm{~mL}$ of a penicillin- $\mathrm{G}$ stock solution $(5000$ units $/ \mathrm{mL}$ ) per $100 \mathrm{~mL}$ of eggs in the egg suspension. The addition of penicillin to the embryological development test has been shown to be beneficial in evalution of the stages of development by inhibiting bacterial growth which can cause the embryos to disintegrate before the test is terminated. 
The penicillin stock solution is prepared by diluting $296 \mathrm{mg}$ of Penicillin-G sodium salt (1690 units/mg) in $100 \mathrm{~mL}$ of MFS and mixing until dissolved. The addition of 2 $\mathrm{mL} / 100 \mathrm{~mL}$ of eggs will result in a final concentration of 4 units $/ \mathrm{mL}$ in each replicate. The number of units of penicillin per $\mathrm{mg}$ of penicillin-G sodium salt is variable with each lot. Thus, the quantity added to the stock will change in order to keep the final concentration at 4 units/mL.

\subsubsection{Obtain Sperm}

Place selected male urchin in a large Carolina dish containing 1-2 cm of water. About half of test should be above water level. Stimulate male with $12 \mathrm{~V}$ transformer, and collect about $0.5 \mathrm{~mL}$ of unwetted sperm from between spines using a pasteur pipette. Place sperm into a plastic microcentrifuge tube. Keep on ice until used. Be careful not to add any water or sperm which has contacted water to the vials. High quality sperm collected dry and kept on ice will last at least eight hours without measurable decline in viability.

\subsubsection{Prepare Appropriate Sperm Dilution}

As in the Sea Urchin Fertilization Test, it is desirable for control fertilization to be 70$90 \%$. Although controls outside these bounds do not automatically disqualify a test, particularly if a valuable dose response is generated, the chance of inducing polyspermy is increased with increased concentrations of sperm, and good dose responses may be difficult to obtain with less than $70 \%$ normal pluteus in controls. Density of sperm in the sperm solution should be determined with this goal in mind. Condition of the animals and length of acclimation to the aquarium may effect the chosen sperm density. The pretest (Attachment 2) may be used to calculate an appropriate sperm dilution. Generally, a dilution of between 1:1250 and 1:7500 will result in desirable fertilization rates, if the animals are in good condition.

For example, if a sperm dilution of 1:5000 is required (as determined from the pretest), add $20 \mu \mathrm{L}$ sperm to $10 \mathrm{~mL}$ MFS. Mix thoroughly, then add $1 \mathrm{~mL}$ of this solution to $9 \mathrm{~mL}$ MFS. Sperm should not be wetted until just before starting the test. Sperm wetted more than 30 minutes before the test has begun, including sperm dilutions used in any pretest, should be discarded and a new dilution made from sperm kept on ice. The quantity of sperm to be added to the egg dilution is calculated by dividing the total volume of eggs by five and adding $50 \mu \mathrm{L}$ of sperm dilution per that number. Sperm should be allowed to incubate with the eggs for 10 minutes to allow fertilization to take place. After 10 minutes, eggs should be evaluated under $100 \mathrm{X}$ magnification for fertilization membranes. If 70-90\% of the eggs are fertilized, the embryos can be pipetted into the test vials. If the percentage is lower than $70 \%$, additional sperm may be added and/or more time allowed for fertilization. If the fertilization does not increase above $70 \%$ after 30 minutes, the embryos should be discarded and new gametes selected for use. Embryos should not be allowed to undergo division before pipetting them into the test vials. 


\subsection{TEST PROCEDURES}

1. While gently swirling the embryo solution to maintain even mixing, use a $200 \mu \mathrm{L}$ pipetter to add $200 \mu \mathrm{L}$ diluted embryo suspension to each vial. Record time of embryo addition.

2. Incubate all test vials at $20 \pm 1$ C for 48 hours.

3. Using the dispenser, add $0.75 \mathrm{~mL} 10 \%$ buffered formalin to each vial.

4. Vials may now be capped and stored overnight or for several days until evaluated.

\subsection{DATA COLLECTION AND TABULATION}

1. Transfer approximately $1 \mathrm{~mL}$ embryos and water from bottom of test vials to counting slide. Observe embryos using a compound microscope under 100X magnification.

2. Count 100 embryos/sample using hand counter with multiple keys (such as a blood cell counter), using one key to indicate normally developed pluteus larvae and others to indicate unfertilized eggs, embryos arrested in earlier developmental stages, and other abnormalities or for more efficient data collection, stages other than pluteus and abnormalities may be lumped together and counted on one key. Attachment 3 has a list of developmental stages and drawings of each.

3. Calculate the proportion of normal plutei for each replicate test:

Number normal plutei X $100=$ Percent normal plutei

Total no. eggs/embryos

\subsection{DATA ANALYSIS}

Data are recorded on standardized data sheets (See Attachments 4-9). Normally, percent normal development (normal plutei) in each treatment is compared to an appropriate reference treatment (seawater, pore water or sea surface microlayer from an uncontaminated environment). Statistical comparisons are made using analysis of variance (ANOVA) and Dunnett's $t$-test (Sokal and Rohlf 1981) on the arc sine square root transformed data. For multiple comparisons among treatments, Ryan's Q test (Day and Quinn 1989) with the arc sine square root transformed data is recommended. The trimmed Spearman-Karber method with Abbott's correction is recommended to calculate $\mathrm{EC}_{50}$ values for dilution series tests (Hamilton et al. 1977). 


\subsection{QUALITY CONTROL}

Quality control tests may be run using both positive and negative controls with multiple replicates (as many as desired). Typically, a reference toxicant dilution series (sodium dodecyl sulfate) is tested with each test to evaluate the gametes chosen. Negative controls may include a reference porewater, filtered seawater, and/or a reconstituted brine.

\subsection{TRAINING}

A trainee will conduct the test with supervision initially. Determining egg concentrations, embryological stages and counts are test specific activities. These functions can be performed independently after a trainee has demonstrated he or she can accurately reproduce the test.

\subsection{SAFETY}

The sea urchin embryological development toxicity test poses little risk to those performing it. Care should be taken when making and dispensing the $10 \%$ buffered formalin solution; use a hood if available, but make sure the test area is well ventilated. Protective gloves can be worn when pipetting or dispensing formalin or potentially toxic samples.

Care should be taken when collecting or otherwise handling sea urchins. Urchin spines are sharp and fragile and may puncture the skin and break off if handled roughly. First aid similar to treatment of wood splinters is effective in this case (removal of spine and treatment with antiseptic). Collection of sea urchins by snorkeling should not be done alone.

\subsection{ATTACHMENTS}

Attachment 1. Equipment List for Embryological Development Toxicity Test

Attachment 2. Pretest to Insure Selection of Quality Gametes

Attachment 3. Development of Sea Urchin Eggs to Pluteus Larvae

Attachment 4. Water Quality Adjustment Data Form

Attachment 5. Sea Urchin Pretest Data Sheet

Attachment 6. Sea Urchin Pretest Continuation Data Sheet

Attachment 7. Sea Urchin Fertilization/Embryological Development Toxicity Test Gamete Data Sheet

Attachment 8. Sea Urchin Embryological Development Test Data Sheet

Attachment 9. Sea Urchin Embryological Development Test Abridged Data Sheet 


\subsection{REFERENCES}

Day, R.W. and G.P. Quinn. 1989. Comparisons of treatments after an analysis of variance in ecology. Ecol. Monogr. 59:433-463.

Hamilton, M.A., R.C. Russo, and R.V. Thurston. 1977. Trimmed Spearman-Karber method for estimating median lethal concentrations in toxicity bioassays. Environ. Sci. Technol. 11(7):714-719; Correction 12(4):417 (1978)

Sokal, R.R., and F.J. Rohlf. 1981. Biometry. $2^{\text {nd }}$ edition. W.H. Freeman and Company, San Francisco, CA 859 pp. 
Prepared by:

Duane Chapman

Fishery Biologist

Approved by:

R. Scott Carr

Field Station Leader

Anne E. Kinsinger

Chief, Field Research Division

Joseph B. Hunn

Quality Assurance Officer 
Attachment 1

\section{EQUIPMENT LIST FOR EMBRYOLOGICAL DEVELOPMENT TOXICITY TEST}

Large Carolina dishes (at least 2)

20 mL KIMBLE scintillation vials (These should be type shipped with caps off, and without cap

liners. If other brand or type is used, the vials should be tested for toxicity prior to use.)

$400 \mathrm{~mL}$ beaker or wide-mouthed thermos for holding vials of sperm

$250 \mathrm{~mL}$ beakers (4)

Pasteur pipettes and latex bulbs

Plastic microcentrifuge tubes

$25 \mathrm{~mL}$ shell vials or equivalent

Test tube rack (to hold shell vials)

$12 \mathrm{~V}$ transformer with pencil type electrodes

Styrofoam (or something to hold electrode tips)

$10 \mathrm{cc}$ syringe with large diameter blunt ended needle (make by grinding sharp point off the needle with a grinding stone)

Marking pens

Ice

$10-100 \mu \mathrm{L}$ pipetter

50-200 $\mu \mathrm{L}$ pipetter

$5 \mathrm{~mL}$ pipetters (2)

Counting slide such as Sedgewick-Rafter chamber

Compound microscope with 10x objective and dark field capability

Hand tally counter

Calculator

Timer for exposure / incubation periods

Buffered formalin and dispenser

Filtered $(0.45 \circlearrowleft \mathrm{m})$ seawater, adjusted to $30 \%$

Data sheets

Baker reagent grade water

Approximately $100 \%$ concentrated brine 
Attachment 2

PRETEST TO INSURE SELECTION OF QUALITY GAMETES

1. Using the procedure in section 2.4.1, select 2 to 5 females and at least 2 male urchins to be used in the pretest.

2. Fill pretest vials with five $\mathrm{mL}$ of reference water. There should be at least two vials for each combination of male, female, and pretest sperm concentration (step 4 below). For example, in a pretest with two females, one male, and six pretest sperm concentrations, 24 vials ( 2 X 2 X 6 ) would be needed. Arrange and mark vials accordingly in a rack.

3. Perform steps 2.4.2 (egg collection) and 2.4.3 (egg dilution) for each female urchin. Make enough volume of the egg suspension to perform the pretest and the test.

4. Perform step 2.4.4 (sperm collection) for each male urchin or male combination. Prepare a dilution series of sperm concentrations which will bracket the $60-90 \%$ fertilization rate in

the test. Sperm dilution will depend on the health and reproductive status of the male urchin, but in most cases the following "standard dilution" should be used:

1:250 (20 $\mu \mathrm{L}$ dry sperm added to $5 \mathrm{~mL}$ MFS. This concentration is used only as stock solution to make up the rest of the dilution series and is not used full strength in the pretest.)

1: 1250 ( $1 \mathrm{~mL}$ of $1: 250$ and $4 \mathrm{~mL}$ MFS)

1: 2500 ( $1 \mathrm{~mL}$ of $1: 250$ and $9 \mathrm{~mL}$ MFS)

1: 5000 ( $2 \mathrm{~mL}$ of $1: 2500$ and $2 \mathrm{~mL}$ MFS)

1: 7500 ( $2 \mathrm{~mL}$ of $1: 2500$ and $4 \mathrm{~mL}$ MFS)

$1: 10000$ ( $3 \mathrm{~mL}$ of $1: 7500$ and $1 \mathrm{~mL}$ MFS)

$1: 12500(1 \mathrm{~mL}$ of $1: 2500$ and $4 \mathrm{~mL}$ MFS)

Sperm must be used within 30 minutes of dilution. Leave undiluted sperm on ice and retain, because a new sperm dilution of the concentration determined in this pretest will be needed for the toxicity test. Sperm diluted for use in the pretest may not be used in the toxicity test, because the time elapsed since the addition of water is too great.

5. As in section 3.0 add $50 \mu \mathrm{L}$ of the diluted sperm to each pretest vial. Incubate for 30 minutes at approximately $20^{\circ} \mathrm{C}$, and add $200 \mu \mathrm{L}$ of the egg suspension. Incubate for another 30 minutes, then fix with $1 \mathrm{~mL}$ of the buffered formalin solution.

6. As in section 4.0, obtain a fertilization rate for the vials. There is no need to count all vials, enough vials should be counted to determine a good male/female combination, and an appropriate sperm dilution factor. If more than one male/female combination is acceptable, this is a good opportunity to choose a female which exhibits easily visible fertilization membranes or in cases where there are many samples, to combine eggs from different females. The appearance of the fertilization membranes may vary among female urchins, and presence of easily visible membranes facilitates counting. 
Attachment 3

\section{DEVELOPMENT OF SEA URCHIN EGGS TO PLUTEUS LARVAE}

The development of sea urchin eggs from fertilization to pluteus larvae normally occurs in approximately 48 hours. Although development is a continuous process of mitosis and cellular differentiation, developmental biology defines distinct stages of development by gross morphological characteristics. For the purpose of the Sea Urchin Embryological Development Test, six stages are defined and used in the characterization of embryos (Drawings on following page).

1. Unfertilized egg - single cell which appears dense and lacks a fertilization membrane.

2. Fertilized egg - egg with a distinct fertilization membrane which appears as a thin band lying slightly away from the central egg. The early stages of cell division are included in this group.

3. Blastula - spherical, "hollow-ball" stage which is ciliated and becomes free-swimming by breaking out of the fertilization membrane.

4. Early gastrula - beginnings of invagination of the blastula wall are evident. Cells move inward (invaginate) to form a central cavity (archenteron). Early gastrula includes embryos with the earliest stages of invagination and continues until the archenteron reaches approximately two-thirds of the diameter of the embryo.

5. Late gastrula - gastrula in which archenteron has developed in length to two-thirds of the embryo diameter and has begun to differentiate and bend towards and break through the embryo wall. Included are the later stages (prism) with primitive gut (complete digestive system), early skeletal rod development, and beginnings of deltoid shape formation.

6. Pluteus - deltoid-shaped larval stage with complete digestive system, skeletal rods, and growth of projecting arms. 
Attachment 4

\section{WATER QUALITY ADJUSTMENT DATA FORM}

STUDY PROTOCOL SAMPLE DESIGNATION

A. Salinity Adjustment:

Initial volume $(\mathrm{mL})$

Initial salinity $(\%)$

Vol. Milli-Q water added (mL)

Vol. _ \% brine added $(\mathrm{mL})$

$\%$ of original sample

(initial vol./final vol. x 100)
INITIALS

DATE

B. Character of Sample (after salinity adjustment):

Volume (mL)

Salinity $(\%)$

$\mathrm{pH}$

Dissolved oxygen (mg/L)

DO saturation (\%)

Total ammonia (mg/L)

Sulfide (mg/L)

\section{COMMENTS}


Attachment 5

SEA URCHIN PRETEST DATA SHEET

TEST ID

INITIALS

STUDY PROTOCOL

DATE

\section{EGGS}

Female number:

Collection time:

Count:

\section{SPERM}

Male number:

Collection time:

Dilution start time:

\section{TEST TIMES}

Sperm in:

Eggs in:

Formalin in:

SPERM DILUTION

COMMENTS

\% FERTILIZATION Reference sample designation:

Female \#

Male \#

\begin{tabular}{lllll} 
Sperm Dilution & REP 1 & REP 2 & REP 3 & REP 4 \\
\hline & - & - & - & - \\
\hline & - & - & - & - \\
\hline \hline
\end{tabular}

\% FERTILIZATION Reference sample designation:

Female \#

Male \#

Sperm dilution

$\begin{array}{ll}\text { REP 1 } & \text { REP 2 } \\ - & - \\ - & -\end{array}$


Attachment 6

SEA URCHIN PRETEST CONTINUATION DATA SHEET

TEST ID

STUDY PROTOCOL

\% FERTILIZATION Reference sample designation:

Female \#

$\underline{\text { Sperm dilution }}$

REP 1

REP 2

Male \#

\% FERTILIZATION Reference sample designation:

Female \#

Male \#

Sperm dilution

REP 1

REP 2

REP 3

REP 4

\% FERTILIZATION Reference sample designation:

Female \#

Male \#

Sperm dilution

$$
\text { REP } 1
$$

REP 2

REP 3

REP 4

\% FERTILIZATION Reference sample designation:

Female \#

Male \#

Sperm dilution

REP 1

REP 2

REP 3

REP 4
INITIALS

DATE 
Attachment 7

\section{SEA URCHIN FERTILIZATION/EMBRYOLOGICAL DEVELOPMENT TOXICITY TEST GAMETE DATA SHEET}

TEST ID

STUDY PROTOCOL
INITIALS

DATE

\section{EGGS}

Collection time:

Initial count/volume:

Final count:

\section{SPERM}

Collection time:

Dilution start time:

Sperm dilution:

Test start temperature:

\section{TEST TIMES}

Box \# $\quad$ Sperm in: $\quad$ Eggs in: $\quad$ Formalin in:

\section{COMMENTS}


Attachment 8

SEA URCHIN EMBRYOLOGICAL DEVELOPMENT TEST DATA SHEET

TEST ID

STUDY PROTOCOL

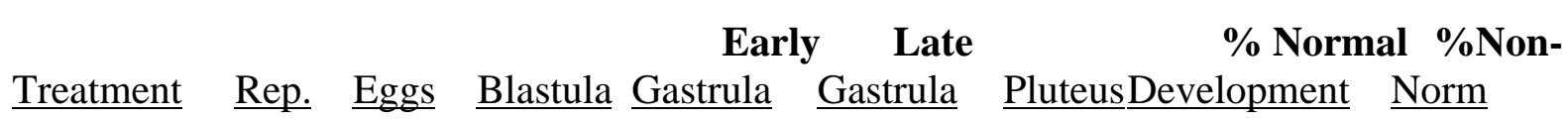

INITIALS

DATE

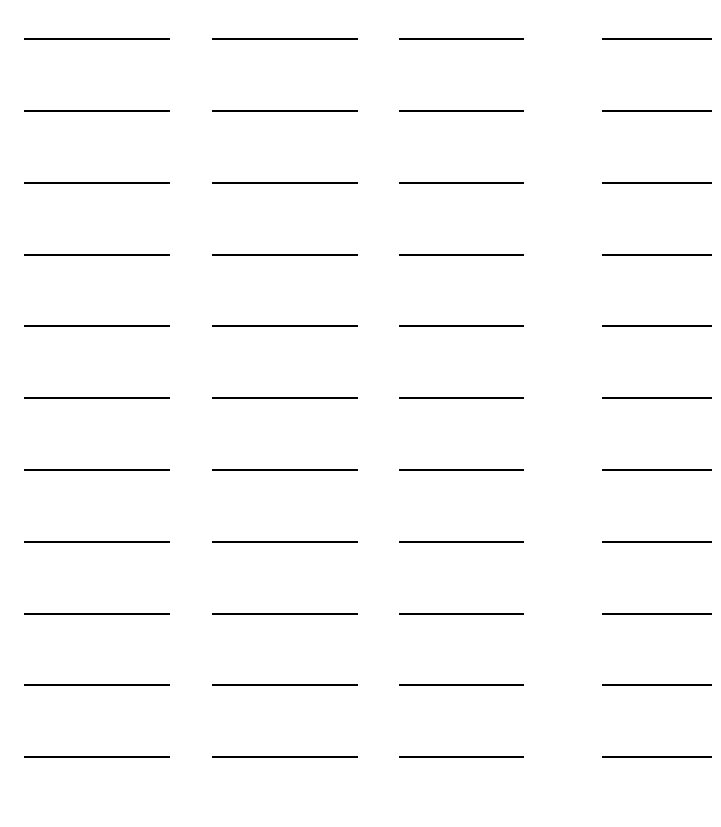

\section{Comments}


Attachment 9

SEA URCHIN EMBRYOLOGICAL DEVELOPMENT TOXICITY TEST DATA SHEET

TEST ID

STUDY PROTOCOL

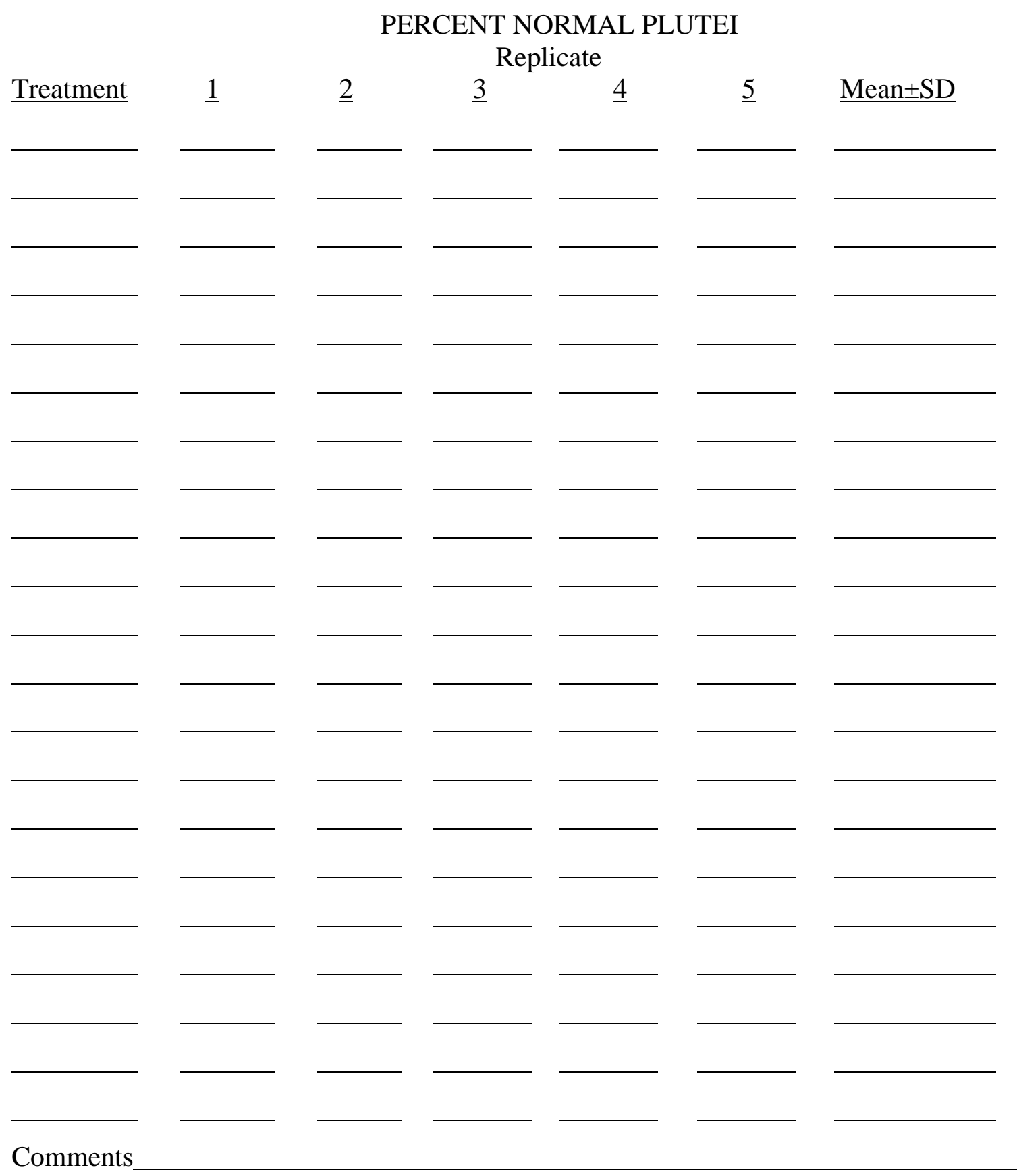

